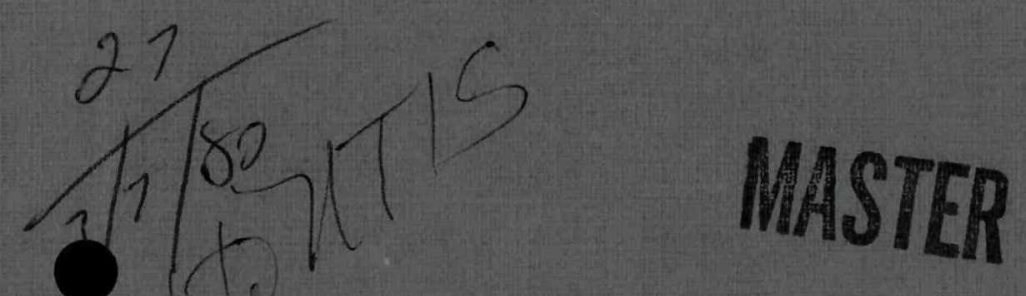

PNL-3204

UC-23

\title{
Stress Analysis and Testing of the Outer Capsule Design for the Strontium Heat Source Development Program
}
F. A. Simonen
R. J. Shippell, Jr.
D. G. Atteridge

January 1980

Prepared for the U.S. Department of Energy under Contract EY-76-C-06-1830

Pacific Northwest Laboratory

Operated for the U.S. Department of Energy by Battelle Memorial Institute 


\section{DISCLAIMER}

This report was prepared as an account of work sponsored by an agency of the United States Government. Neither the United States Government nor any agency Thereof, nor any of their employees, makes any warranty, express or implied, or assumes any legal liability or responsibility for the accuracy, completeness, or usefulness of any information, apparatus, product, or process disclosed, or represents that its use would not infringe privately owned rights. Reference herein to any specific commercial product, process, or service by trade name, trademark, manufacturer, or otherwise does not necessarily constitute or imply its endorsement, recommendation, or favoring by the United States Government or any agency thereof. The views and opinions of authors expressed herein do not necessarily state or reflect those of the United States Government or any agency thereof. 


\section{DISCLAIMER}

Portions of this document may be illegible in electronic image products. Images are produced from the best available original document. 


\title{
NOTICE
}

This report was prepared as an account of work sponsored by the United States Government. Neither the United States nor the Department of Energy, nor any of their employees, nor any of their contractors, subcontractors, or their employees, makes any warranty, express or implied, or assumes any legal liability or responsibility for the accuracy, completeness or usefulness of any information, apparatus, product or process disclosed, or represents that its use would not infringe privately owned rights.

The views, opinions and conclusions contained in this report are those of the contractor and do not necessarily represent those of the United States Government or the United States Department of Energy.

\author{
PACIFIC NORTHWEST LABORATORY \\ operated by \\ BATTELLE \\ for the \\ UNITED STATES DEPARTMENT OF ENERGY \\ Under Contract EY-76-C-06-1830
}

\author{
Printed in the United States of America \\ Available from \\ National Technical Information Service \\ United States Department of Commerce \\ 5285 Port Royal Road \\ Springfield, Virginia 22151 \\ Price: Printed Copy $\$$. \\ $\therefore$ Microfiche $\$ 3.00$ \\ NTIS \\ - Pages Selling Price \\ $001-025 \quad \$ 4.00$ \\ $026-050 \quad \$ 4.50$ \\ $051-075 \quad \$ 5.25$ \\ $076-100 \quad \$ 6.00$ \\ $101-125 \quad \$ 6.50$ \\ $126-150 \quad \$ 7.25$ \\ $151-175 \quad \$ 8.00$ \\ $176-200 \quad 59.00$ \\ 201-225 $\quad \$ 9.25$ \\ $226-250 \quad \$ 9.50$ \\ 251-275 \$10.75 \\ $276-300 \quad \$ 11.00$
}


PNL-3204

$\mathrm{UC}-23$

STRESS ANALYSIS AND TESTING

OF THE OUTER CAPSULE DESIGN

FOR THE STRONTIUM HEAT SOURCE

DEVELOPMENT PROGRAM

F. A. Simonen

R. J. Shippel1, Jr.

D. G. Atteridge

January 1980

Prepared for

the U.S. Department of Energy

Under Contract EY-76-C-06-1830

Pacific Northwest Laboratory

Richland, Washington 99352

Ths s book wes prepared as an account of work sponsored by an agency of the United States Government
We ther the Un ed States Government nor any atency the W rranty express or implied or assu nes agency thereof nor any of their employees makes any compluteness or use untress of any informat on aparatus or respons bill ty for the accurdey cejresents that ts use woutd not iffenge privately owned r ghts Reference process d sclosed of

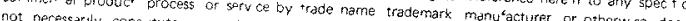
States Gosant cons itute or mply ts endorsement recommendat on or favoting serw se does 
page blank

ii 
SUMMARY

The objective of the Strontium Heat Source Development Program is to obtain the data needed to license ${ }^{90} \mathrm{SrF}_{2}$ heat sources -- specifically the ${ }^{90} \mathrm{SrF}_{2}$ capsules produced in the Waste Encapsulation and Storage Facility (WESF) at Hanford. Toward this end, a high integrity outer capsule has been designed to replace the present outer capsule of the WESF ${ }^{90} \mathrm{SrF}_{2}$ capsule.

This report describes the proposed design of a Hastelloy $S^{\circledR}$ outer capsule which features a mechanical interlock type of end closure. Qualification testing requirements are outlined, and stress analyses and developmental tests are described. These tests were performed on AISI-1018 steel stand-in capsules, and included both external pressure and impact tests. The external pressure tests showed that stress calculations seriously overestimated the pressure capability of the outer capsule. Possible reasons for the lack of agreement between the tests and the analyses are evaluated.

The stress analyses and test results indicate that the proposed outer capsule will meet the heat source qualification requirements. Future tests will be conducted to experimentally verify that the Hastelloy $S$ outer capsule in an aged condition meets the structural integrity requirements.

\footnotetext{
Hastelloy is a trade name of the Stellite Division, Cabot Corporation.
} 
page blank 


\section{CONTENTS}

SUMMARY. . . . . . . . . . . . . . . . . . . . . . . i i

FIGURES. . . . . . . . . . . . . . . . . . . . . . vii

TABLES........................... . . ix

INTRODUCTION . . . . . . . . . . . . . . . . . . . . . 1

DESIGN CALCULATIONS FOR EXTERNAL PRESSURE. . . . . . . . . . . . . 5

DESIGN EQUATIONS FOR EXTERNAL PRESSURE RESISTANCE . . . . . . . 5

Elastic and Plastic Instability. . . . . . . . . . . . 5

Elastic Stresses................. 7

Fully Plastic Condition. .. . . . . . . . . . . 7

An Empirical Equation. . . . . . . . . . . . . . . 7

Average Wall Stresses. . . . . . . . . . . . . 8

Finite Element Solutions ................. 9

ASME Code and Experimental Data. . . . . . . . . . . . 9

FINITE ELEMENT WALL COLLAPSE ANALYSIS . . . . . . . . . . . . . 9

PRELIMINARY EVALUATION OF REQUIRED WALL THICKNESS . . . . . . . . 12

EXPERIMENTAL EVALUATION OF EXTERNAL PRESSURE CAPABILITY. . . . . . . . 15

MATERIAL CHARACTERIZATION . . . . . . . . . . . . 15

TEST PROCEDURE. . . . . . . . . . . . . . . . . . . 17

RESULTS OF CAPSULE PRESSURE TESTS . . . . . . . . . . . . . . 20

PREDICTED VERSUS EXPERIMENTAL COLLAPSE. . . . . . . . . . . . 24

POSSIBLE SOURCES OF ERROR . . . . . . . . . . . . . . . . 29

Geometric Imperfections. . . . . . . . . . . . . 30

Anistropy. . . . . . . . . . . . . . . . . 30

Instrumentation Errors . . . . . . . . . . . . . 30

Heat Treatment Not as Specified.. . . . . . . . . . . 31

Identification of Compression Specimens. . . . . . . . . 37

End Cap Effects. . . . . . . . . . . . . . . . 31

Detection of Yielding in Capsules. . . . . . . . . . . 32

Residual Stresses. . . . . . . . . . . . . . . 32

Yield Criteria ... . . . . . . . . . . . . . 32

Discussion .................. 33 
END CLOSURE CONFIGURATION DETERMINATION. . . . . . . . 35

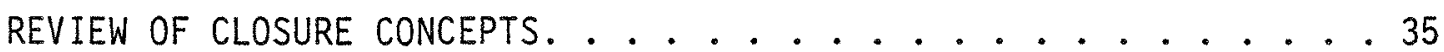

FINITE ELEMENT END CLOSURE DESIGN IMPACT ANALYSIS . . . . . . 38

FINITE ELEMENT END CLOSURE DESIGN EXTERNAL PRESSURE ANALYSIS. . . 41

IMPACT AND PUNCTURE TESTS. . . . . . . . . . . . . . . 45

DROP TESTS OF AISI-1018 STEEL CAPSULES. . . . . . . . . 45

PUNCTURE TESTS OF AISI-1018 STEEL CAPSULES. ......... 53

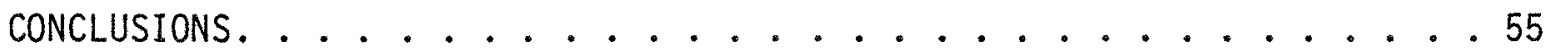

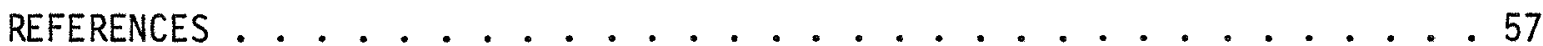

APPENDIX - QUALIFICATION TESTING REQUIREMENTS FOR THE ${ }^{90} \mathrm{SrF}_{2}$ HEAT

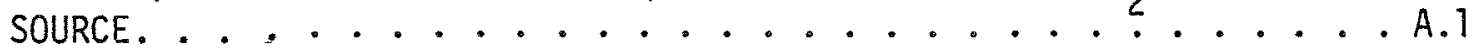




\section{FIGURES}

1 Basic Capsule Design for the Waste Encapsulation and Storage Facility . . . . . . . . . . . . . . . . . . . 2

2 External Pressure Analys is of Tube . . . . . . . . . . . . 6

3 Finite Element Model of External Pressure Collapse Calculations. . 10

4 Calculated Pressure Deflection Curves for Oval ized Capsules. . . . 11

5 Tensile Stress-Strain Curve for AISI-1018 Carbon Steel Tubing. . . 16

6 Pressure Test Capsule. . . . . . . . . . . . . . . 18

7 Outer Capsule Components and Completed AISI-1018 Steel Outer Capsule Ready for External Pressure Testing. . . . . . . . . . . 19

8 Steel Capsules After Pressure Testing. . . . . . . . . . . . . 21

9 Measured Average Diameter Changes in AISI-1018 Steel Test Capsules....................... 2. 22

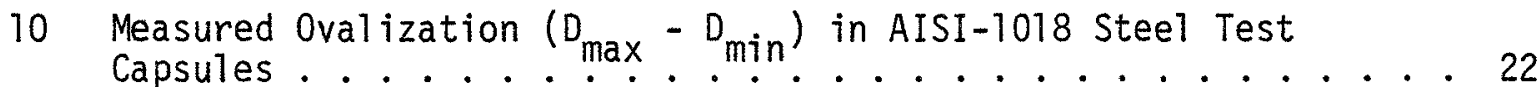

11 Experimental Yield and Collapse Pressures for AISI-1018 Stee1 Test Capsules. . . . . . . . . . . . . . . . . . 23

12 Strain Grid Data From Outer Surface of 0.5-In. Wa11 Capsule. . . 25

13 Comparison of Predicted and Measured Vield Pressures for AISI-1018 Steel Test Capsules. . . . . . . . . . . . . 26

14 Comparison of Predicted and Measured Average Diameter Changes for AISI-1018 Steel Test Capsules. . . . . . . . . . . . . 28

15 Comparison of Predicted and Measured Ovalization of AISI-1018 Steel Test Capsules. ................. . 28

16 Typical Capsule Closure Concepts (Grove et a1 1965) . . . . . . 36

17 Effect of Corner Impact on Closure Welds . . . . . . . . . . 36

18 Proposed Outer Capsule for Hanford Waste Encapsulation and 37

19 Finite Element Model for Impact Analys is of Interlocking End Cap. . . . . . . . . . . . . . . . . . . . 39

20 Predicted Deformation of Noninterlocking End Cap for End Impact of 30-Ft Drop................. . . 40 40

21 Predicted Deformation of Interlocking End Cap For End Impact of 30-Ft Drop...................... . . 40 40

22 ADINA Model for Analysis of Pressure-Induced End Closure Stresses........................ 41 
23 Predicted Deflection of Capsule for External Pressure of 14,500 psi $(0.6-$ In. Wa11) . . . . . . . . . . . 42

24 Calculated Contours of Effective Stress in Capsule End Cap for External Pressure of 14,500 psi (0.6-In. Wall). . . . . 43

25 Photomicrograph of Full Penetration Closure Weld in AISI-1018 Steel Stand-In Outer Capsule (8x) . . . . . . . . . . 46

26 Thirty-Foot Drop Test of an AISI-1018 Steel Capsule . . . . . . 47

27 Charpy Impact Energy for AISI-1018 Steel Outer Capsule Components . 48

28 AISI-1018 Steel Stand-In Outer Capsule After Drop Test at $15^{\circ} \mathrm{F}$. . . 50

29 Impacted Corner of the AISI-1018 Steel Stand-In Outer Capsule Showing S1ight Deformation After Drop Test at $15^{\circ} \mathrm{F}$. . . . . . . 51

30 AISI-1018 Steel Stand-In Outer Capsule Tested at Liquid Nitrogen Temperature Showing Complete Brittle Failure of End Cap . . . . . . 52

31 Locations of Three Puncture Tests on the Steel Stand-In Capsule . . 53 


\section{TABLES}

1 Required Capsule Dimensions to Avoid Local Plastic Deformation at Capsule Inside Diameter for External Pressure of 14,500 psi

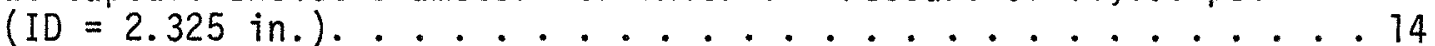

2 Required Capsule Dimensions to Avoid Fully Plastic Condition of Capsule Wall for External Pressure of 14,500 psi $(I D=2.325$ in. $) .. . . . . . . . . . . . .14$

3 Yield Strengths of AISI-1018 Carbon Steel Tubing Material . . . . 16

4 Capsule Dimensions and Experimental Failure Pressures . . . . . . 23 


\section{STRESS ANALYSIS AND TESTING OF THE OUTER CAPSULE DESIGN \\ FOR THE \\ STRONTIUM HEAT SOURCE DEVELOPMENT PROGRAM}

\section{INTRODUCTION}

Rockwe11 Hanford Operations recovers ${ }^{90} \mathrm{Sr}$ from nuclear reprocessing wastes as part of the U.S. Department of Energy (DOE) waste management program at Hanford. The ${ }^{90} \mathrm{Sr}$ is converted into strontium fluoride, double encapsulated in high integrity containers, and stored in water basins at Hanford. The ${ }^{90} \mathrm{SrF}_{2}$ preparation, encapsulation, and storage take place in the Waste Encapsulation and Storage Facility (WESF).

Under DOE sponsorship, the Pacific Northwest Laboratory undertook to study using the ${ }^{90} \mathrm{SrF}_{2}$ as a heat source for a heat engine. One of the tasks is to develop data needed to 1 icense ${ }^{90} \mathrm{SrF}_{2}$ heat sources for terrestrial applications. To accomplish this required defining a licensing qualification test matrix and designing a capsule capable of meeting these requirements. The heat source qualification test requirements are listed in the Appendix. These requirements are to be met in both the "as-fabricated" and "post-service" condition.

One of the major objectives of the heat source development program is to use as much of the existing WESF ${ }^{90} \mathrm{SrF}_{2}$ storage capsule, shown in Figure 1 , as possible. Thus, it was decided to use, at a minimum, the inner WESF capsule. It was also decided that support for the outer capsule potentially provided by the inner capsule is not to be considered in meeting the licensing requirements, particularly as it applies to the external pressure requirement. This is made necessary by the potential embrittlement and weakening of the Hastelloy ${ }^{\circledR} \mathrm{C}-276$ inner capsule during heat source service. This inner capsule degradation would result from attack by the contained ${ }^{90} \mathrm{SrF}_{2}$ and embrittlement due to aging reactions, which are known to occur in Hastelloy C-276 at the expected use temperature. The outer

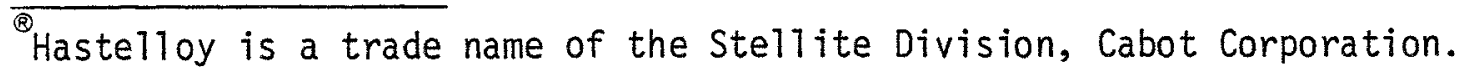




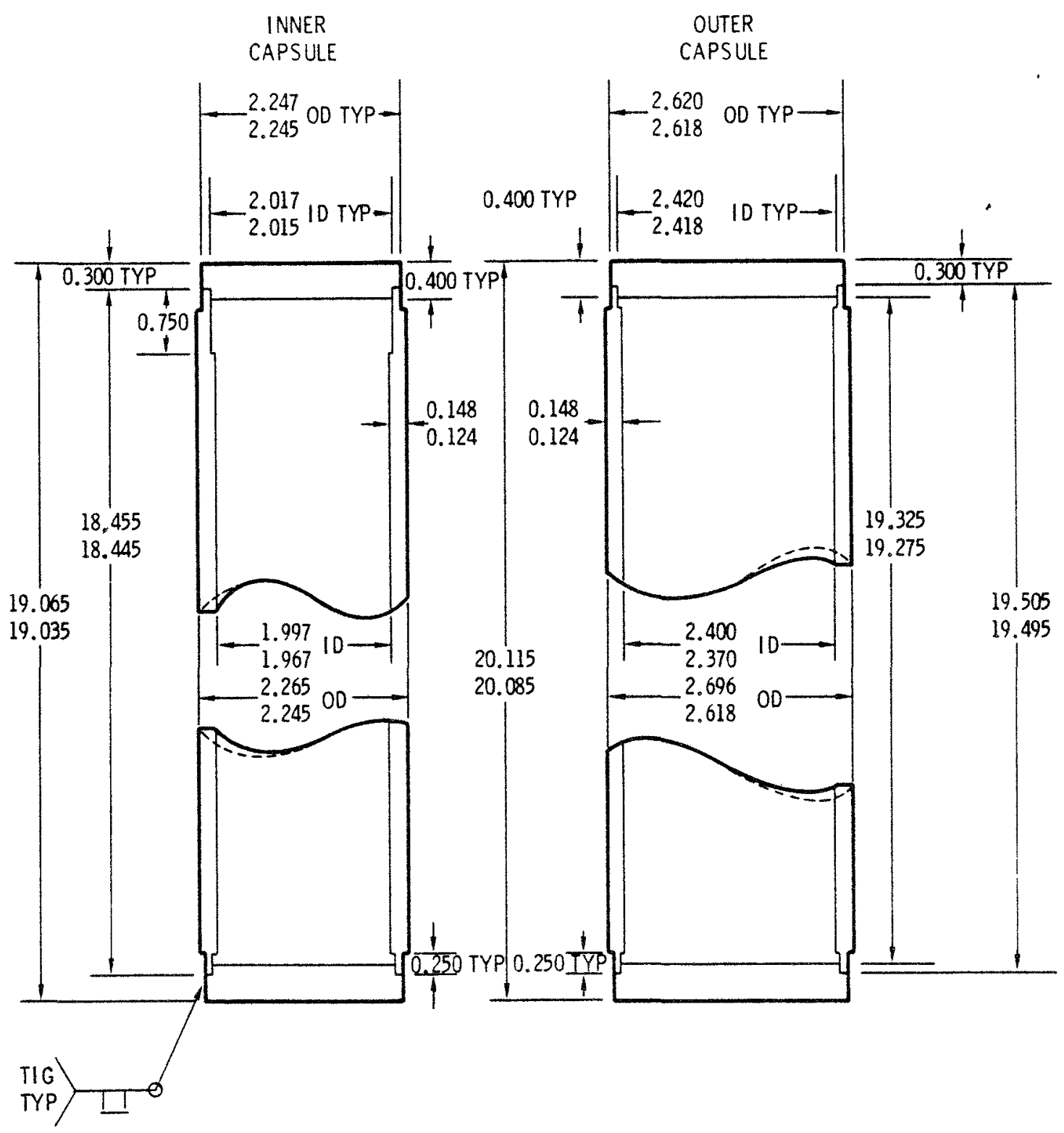

DIMENSIONS: INCHES

DIAMETRAL CLEARANCE BETWEEN CAPSULES $=\begin{aligned} & 0.155 \\ & 0.105\end{aligned}$

LONGITUDINAL CLEARANCE BETWEEN CAPSULES $=\begin{aligned} & 0.290 \\ & 0.210\end{aligned}$

TUBING ECCENTRICITY $= \pm 10 \%$ OF NOMINAL WALL THICKNESS

INNER CAPSULE - HASTELLOY C - 276

OUTER CAPSULE - 316 L STAINLESS STEEL

FIGURE 1. Basic Capsule Design for the Waste Encapsulation and Storage Facility 
WESF capsule was initially fabricated from Hastelloy $\mathrm{C}-276$, but is now 316L staintess steel.

Inadequacies in the current WESF outer capsule for heat source service were identified, primarily its inability to sustain an external pressure of $14,500 \mathrm{psi}$ (1000 bar). Thus, it was determined that a new outer capsule would be needed for the heat source to pass the licensing tests. This report is concerned with the design and qualification of an outer capsule for the heat source that will replace the current outer capsule of the stored strontium material. Actual qualification of the outer capsule design will be based on physical tests. The analyses and developmental tests reported here are intended to serve as a guide to capsule design and fabrication, and to ensure a high probability that future qualification tests of prototype capsules will be passed.

The first two qualification test requirements listed in the Appendix will most severely test the integrity of the capsule. In this study, therefore, stress analyses focused on the 14,500-psi external pressure and 30-ft drop impact loadings. The capsule wall thickness was determined by considerations of the collapse condition for external pressure. The 30-ft drop condition results in maximum damage for an impact on the capsule corner, and consequently, the corner joint design is dictated by the loading encountered during impact.

The selection of the outer capsule material was based on consideration of high-temperature mechanical properties, thermal stability, oxidation and seawater corrosion resistance, availability, weldability, and compatibility with the Hastelloy C-276 inner capsule. Long-term high-temperature compatibility with ${ }^{90} \mathrm{SrF}_{2}$ is not a selection criterion because the ${ }^{90} \mathrm{SrF}_{2}$ is not expected to contact the outer capsule under normal operating service. Four principal candidates were considered for use as the outer capsule material: Hastelloy S, Hastelloy C-4, Inconel 625, and Inconel 617. Hastelloy $S$ was selected for use, based on its preferred high-temperature aging characteristics. Hastelloy $\mathrm{C}-4$ was chosen as a back-up material. 
This report documents the rationale for the selection of the outer capsule wall thickness and the capsule end closure design. The factors governing capsule failure under external pressure and impact loadings are discussed. Also described are results of finite element stress analyses, which evaluate the ability of the capsule to sustain the required pressure and impact loadings. Impact and external pressure tests are described for capsules of AISI-1018 carbon steel. This material was selected as a stand-in for a prototype capsule of Hastelloy S, which, in an aged condition, will have a similar yield strength of 40,000 psi. It was found in the external pressure tests that yield pressures for the test capsules were significantly lower than predicted by design equations. Possible reasons for this lack of agreement are discussed. 


\section{DESIGN CALCULATIONS FOR EXTERNAL PRESSURE}

The 14,500-psi external pressure requirement dictated a relatively thick-walled capsule. It was, therefore, essential to establish failure pressures with some precision to avoid an unnecessary penalty in terms of capsule size and weight. Unfortunately, design equations for thick-walled tubing in the wall thickness and pressure range of interest are decidediy lacking, as are experimental results for external collapse pressures. The approach taken was to first systematically apply and interpret published design equations and experimental results. In addition, detailed finite element analyses were performed to evaluate geometric and material variables. Once a preliminary wall thickness was established, external pressure tests were performed on the experimental capsules. The final wall thickness specification was based on the results of these tests.

\section{DESIGN EQUATIONS FOR EXTERNAL PRESSURE RESISTANCE}

A number of equations are available to predict elastic stresses, yielding and instability or buckling of tubes under external pressure. Several of these equations are cited and interpreted below.

\section{Elastic and Plastic Instability}

For relatively thin-walled tubing, external pressure collapse occurs in the form of an elastic instability. In analytical treatments, as presented by Timoshenko and Gere (1961), an initial geometric imperfection is taken to be in the form of cross section ovalization. Application of external pressure causes an increase in ovalization, and, at a critical pressure, collapse occurs in the form of tube flattening. In terms of definitions given in Figure 2 , the theoretical collapse pressure occurs for a critical pressure of

and

$$
p_{c r}=\frac{2 h_{\sigma_{c r}}}{D_{0}}
$$

$$
\sigma_{c r}=\frac{E}{1-v^{2}}(h / 2 R)^{2}
$$

where $\sigma_{\mathrm{cr}}$ is the critical stress for collapse and $\nu$ is Poisson's ratio. 


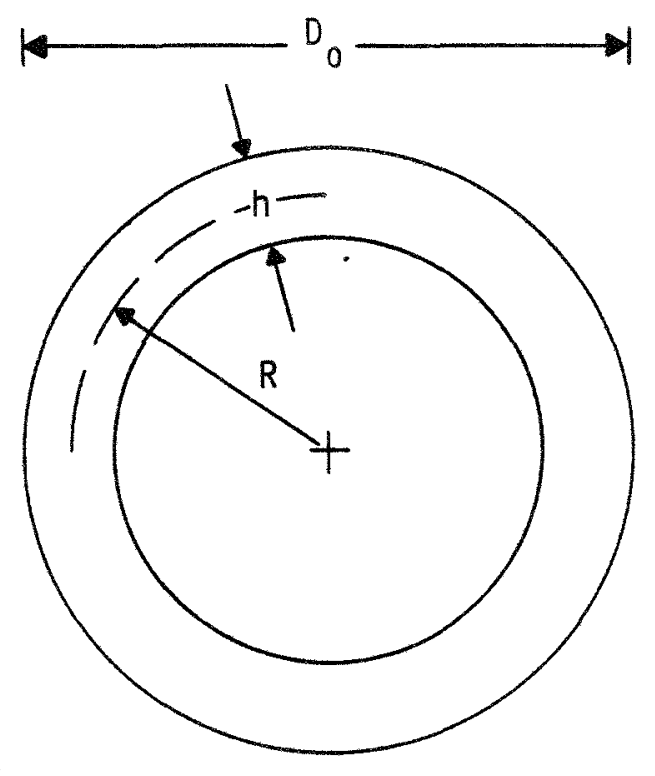

TUBE CONFIGURATION

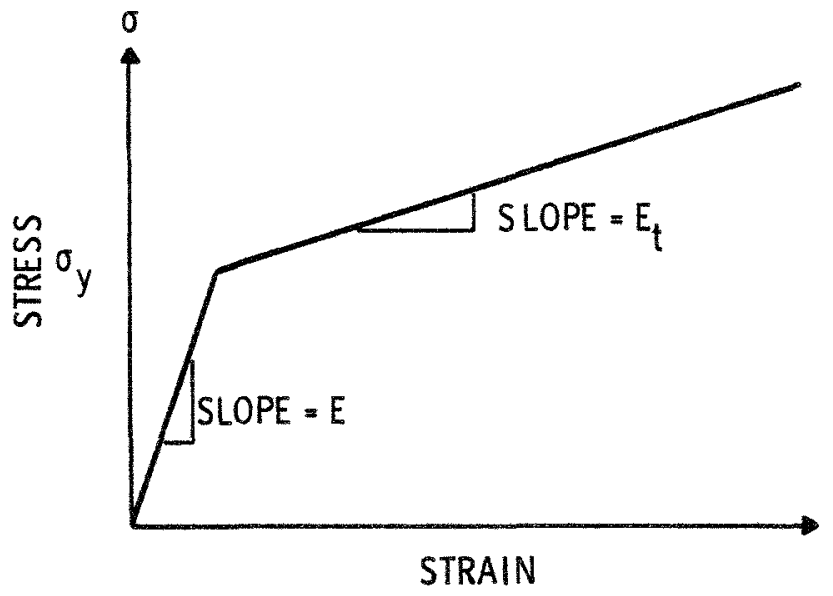

STRESS STRAIN CURVE

\section{FIGURE 2. External Pressure Anatys is of Tube}

For thicker-walled tubes, yielding occurs before the critical pressure is attained and Equation (2) is no longer valid. However, Timoshenko and Gere suggest using a tangent modulus equation,

$$
\sigma_{c r}=\frac{E_{t}}{1-v^{2}}(h / 2 R)^{2}
$$

where $E_{t}$ is the slope of the stress strain curve in the plastic range, and Poisson's ratio in the plastic range may be taken as 0.5 . It is implied that the tube will plastically deform inward in a stable manner without catastrophic ovalization if the conditions of Equation (3) are met. It is also implied that the pressure is sufficiently high to cause the entire wall thickness of the tube to yield.

The stability criterion of Equation (3) is based on thin-wall considerations. For the current capsule thicknesses, the equation indicates the 
important material and geometric parameters governing ovalization. However, numerical predictions of collapse pressures are likely to be approximate.

\section{Elastic Stresses}

For thick-walled cylinders in plane strain, Timoshenko and Goodier (1951) give the equations for the elastic stresses in a thick-walled cylinder. Yield will occur first at the inside diameter of the tube when the hoop stress equals the material yield strength. The yield pressure $P_{y}$ is

$$
P_{y}=\sigma_{y}\left(b^{2}-a^{2}\right) / 2 b^{2}
$$

where $a$ and $b$ are the inner and outer radii of the tube, respectively. Yield in Equation (4) is based on the Tresca or maximum shear stress criterion for yield. For a given inside diameter, the required outside tube radius to avoid yield is

$$
b=a \sqrt{\sigma_{y} /\left(\sigma_{y}-2 P\right)}
$$

\section{Fully Plastic Condition}

Davidson et al. (1959) derive equations for the post-yield or plastic range for internal pressure loading. The Tresca yield condition is assumed. These derivations were extended in this study to cover the condition of external pressure. Details are omitted here. The fully plastic condition of the tube wall occurs for a pressure of

$$
P_{L}=\sigma_{y} \ln (b / a)
$$

Further, the outside tube radius to avoid the fully plastic condition for pressure of $P_{L}$ is

$$
b=a \exp \left(P_{L} / \sigma_{y}\right)
$$

\section{An Empirical Equation}

An empirical equation can be used as a conservation design basis for elastic-plastic design. This equation (Timoshenko and Gere 1961) has the form 


$$
\sigma_{c r}=\sigma_{y} /\left[1+\frac{\sigma_{y}\left(1-v^{2}\right)}{E} \frac{4 R^{2}}{h^{2}}\right]
$$

For thin-walled tubes, this equation reduces to the elastic buckling Equation (1). In this study, Equation (8) was thought to be too conservative to precisely define wall thickness requirements.

\section{Average Wall Stresses}

The foregoing equations for plastic conditions are based on the Tresca yield criterion. For the PNL study, the criterion implies that yield is not affected by axial stresses in the tube. In estimating the possible effect of axial stresses using the von Mises yield criterion, average stresses in the wall of the tube were used.

Equations for average stresses through the wall of the capsule were formulated in terms of the wall thickness, $t$, outside diameter, $D_{0}$, the inside diameter, $D_{j}$, and the external pressure, $P_{0}$, as follows:

$$
\begin{aligned}
& \sigma_{r}=\text { radial stress }=-P_{0} / 2 \\
& \sigma_{\theta}=\text { hoop stress }=-P_{0} D_{0} / 2 t \\
& \sigma_{z}=\text { axial stress }=-P_{0} D_{0}^{2} /\left(D_{0}^{2}-D_{i}^{2}\right)
\end{aligned}
$$

Effective stresses to evaluate pressures that produce plastic conditions in the capsule were defined as:

von Mises Stress

$$
2 \sigma^{2}=\left(\sigma_{r}-\sigma_{\theta}\right)^{2}+\left(\sigma_{r}-\sigma_{z}\right)^{2}+\left(\sigma_{\theta}-\sigma_{z}\right)^{2}
$$

\section{Tresca Stress}

$$
\bar{\sigma}=\sigma_{\theta}-\sigma_{r}
$$

Yield in the full wall of the capsule was taken to occur when the pressure was sufficient to increase the effective stress $\bar{\sigma}$ to the material yield strength. 
Finite Element Solutions

The finite element code ADINA (Bathe 1976) was used to model the capsule geometries including end caps. Incremental elastic-plastic analyses were performed based upon the von Mises yield criterion with isotropic strain hardening. These finite element calculations were considered more rigorous than the approximate equations and were expected to agree best with the experimental results. However, as explained in subsequent sections of this report, the opposite trend proved to be the case. Nevertheless, much useful information was obtained on the importance of such factors as end effects, axial stresses, geometric imperfections, and strain hardening.

ASME Code and Experimental Data

The ASME Boiler and Pressure Vessel Code (1977) provides design charts for external pressure loading. These charts are limited to relatively large diameter-to-thickness $(D / t)$ ratios and contain inappropriately large safety factors. Heise and Esztergar (1970) review elastic-plastic tube collapse with reference to the ASME code. Experimental data are cited strongly suggesting that, for the $D / t$ ratios of interest to this study, collapse will occur only after the wall of the tube wall has yielded entirely from its inside to outside diameter. Additional experimental data of interest are cited by Livsey and Janejo (1976) with regard to heat exchanger tubes with ovality and simulated defects. For the tube thicknesses of interest, their data show that collapse pressures are relatively insensitive to geometric imperfections.

\section{FINITE ELEMENT WALL COLLAPSE ANALYSIS}

Due to a lack of design data for the diameter-to-thickness ratios of interest, finite element analyses were performed early in the design effort for a representative wall thickness. Figure 3 shows a finite element representation of a generic capsule cross section. The specific dimensions were an inside diameter of $2.4 \mathrm{in}$. and a 0.6-in. wall thickness. Because the purpose of the finite element analys is was to study plastic collapse phenomena and to perform sensitivity analyses, the exact dimensions were not critical to the objective of this particular investigation. In a later 


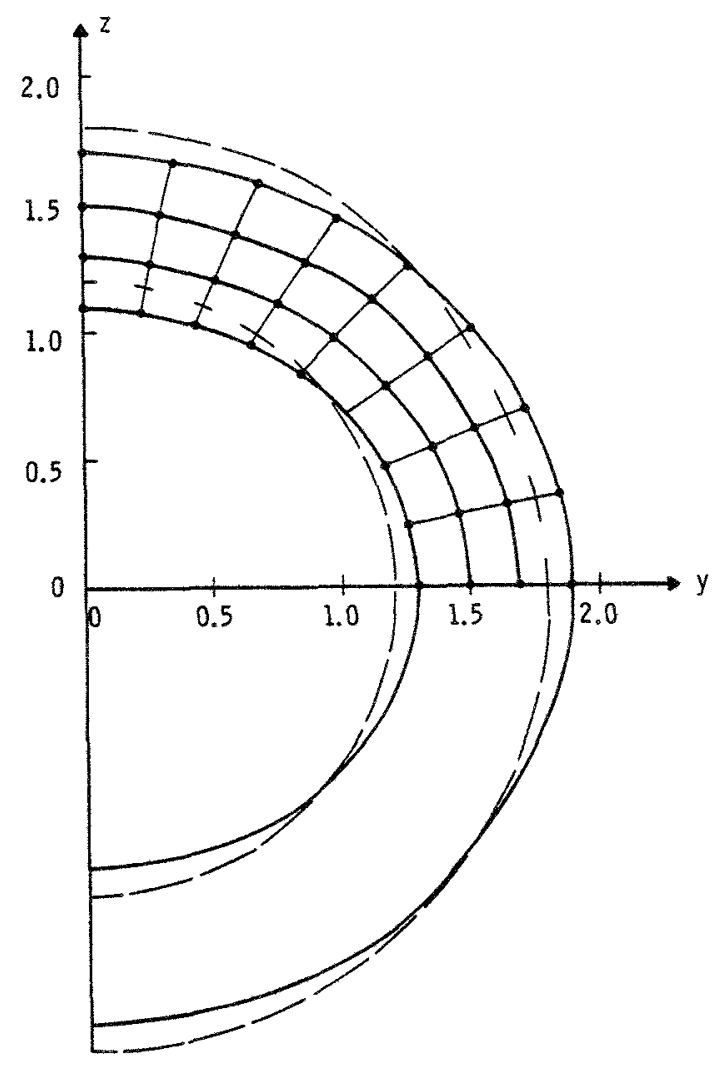

\section{FIGURE 3. Finite Element Model of External Pressure Collapse Calculations}

phase of the research program, exact dimensions and imperfections of an experimental capsule were modeled. These results are reported below and compared with experimental results.

The computer program ADINA (Bathe 1976) was used in the analyses. This program has a full nonlinear stress analysis capability. Both material (plastic deformation) and geometric nonlinearities (shape changes) are treated. The geometric or large deflection capability allowed the effects of initial imperfections in the form of cross section ovality to be treated. With the elastic-plastic capability, the effects of different levels of plastic strain hardening were studied.

Figure 4 shows calculated pressure deflection curves (decrease in minor radius) for the ovalized capsules, where the initial ovalization on radius 


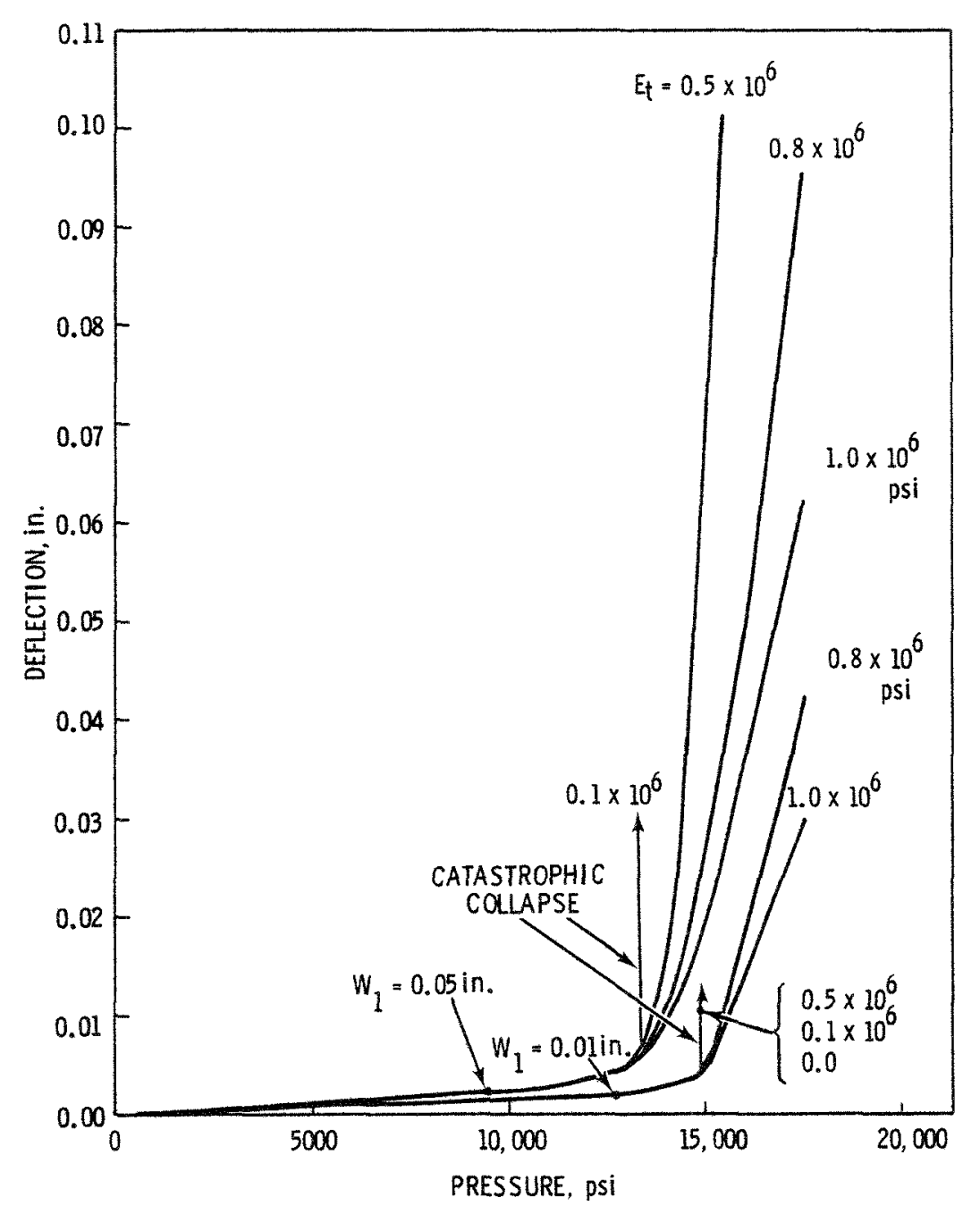

FIGURE 4. Calculated Pressure Deflection Curves for Ovalized Capsules

was of the form

$$
W=W_{1} \cos \theta
$$

The values of $W=0.01$ and 0.05 inch in Figure 4 imply that the major diameter is greater than the minor diameter by 0.04 and $0.20 \mathrm{in}$, respectively. The calculations were for a yield strength of 42,000 psi and for various degrees of strain hardening $\left(E_{t}=0.0,0.1 \times 10^{6}, 0.5 \times 10^{6}\right.$, $0.8 \times 10^{6}$, and $\left.1.0 \times 10^{6} \mathrm{psi}\right)$. The analyses were for a planar slice with 
zero axial stress, and as such, tended to underestimate collapse pressure and the effects of triaxial stress.

A five-fold increase in ovality (from 0.01 to 0.05 ) resulted in a reduction in predicted collapse pressure of about $12 \%$ (from about 15,000 psi to $13,500 \mathrm{psi}$ ). This indicated that, for this $\mathrm{D} / \mathrm{t}$ ratio, the collapse pressure is relatively insensitive to imperfections. Imperfections in the form of ovality are reported in the literature to have the greatest effect on collapse pressure. In every case of this study, the abrupt loss of pressure-carrying ability correlated with the local formation of a fully plastic cross section. The vertical trend of certain curves in Figure 4 for low strain hardening indicates those cases for which the finite element solution became numerically unstable, which implies catastrophic flattening of the cross section. With adequate strain hardening it was possible to continue the numerical solution into the post-collapse range. The critical level of strain hardening constant $\left(E_{t}\right)$ corresponded approximately to that predicted by Equation (3) for plastic stability.

The results of the ovality studies indicated that the degree of ovality anticipated for the capsules should have an insignificant effect on pressure capability. It appears reasonable and conservative to design on the basis of pressures to produce a fully plastic condition in an ideal or nonovalized cross section.

\section{PRELIMINARY EVALUATION OF REQUIRED WALL THICKNESS}

The qualification testing requirements state only that the outer capsule shall not leak following the external pressure test. Plastic collapse per se is acceptable, provided the capsule does not rupture. However, in the post-service condition, the capsule material will be aged and may have 1 imited ductility. It was, therefore, decided that large scale plastic deformation should be avoided if capsule rupture is to be prevented.

Application of Equations (1) and (2) for predicting elastic buckling 1 imits indicated that the wall thickness range of interest precludes failure 
by this mode. Attention was then directed to pressure-wall thickness relationships for plastic deformation and collapse.

In designing the outer capsule for external pressure, the following general considerations were adopted:

- Because the wall thicknesses of interest were outside the domain of accepted design codes, final verification and selection of wall thicknesses must be based on developmental testing.

- No support from the inner capsule is to be considered.

- Yielding of the capsule is permitted, but plastic strain levels must be minimized.

- The external pressure requirement is to be met at room temperature.

- Plastic buckling will not occur until the entire cross section of the tube wall becomes plastic at one or more circumferential locations.

- Uncertainties exist regarding the aged stress-strain properties of the capsule material; thus, plastic buckling cannot be designed against on the basis that the aged material will have an adequate level of strain hardening.

Minimum wall thicknesses required to avoid yielding at the inside surface of the tube are 1 isted in Table 1, as predicted by Equations (4) and (5), which are based on the Tresca yield criterion. Four candidate capsule materials along with their estimated minimum yield strengths are listed. To avoid yielding at the bore surface at an external pressure of 14,500 psi, wall thicknesses approaching $1.0 \mathrm{in}$. are required.

Applying Equation (7) gives the wall thickness required to prevent the fully plastic condition through the wall of the capsules. In accordance with Davidson et a1. (1959), biaxial stress effects as predicted by the von Mises yield condition were considered by replacing $\sigma_{y}$ with $1.15 \sigma_{y}$ in Equation (7). The results shown in Table 2 show that a wall thickness of about $0.4 \mathrm{in}$. should, in theory, be adequate to prevent the development of a fully plastic condition through the tube wall for all of the candidate materials. 
TABLE 1. Required Capsule Dimensions to Avoid Local Plastic Deformation at Capsule Inside Diameter for External Pressure of 14,500 psi (ID $=2.325$ in.)

\begin{tabular}{|c|c|c|c|}
\hline Material & $\begin{array}{c}\text { Yield Strength } \\
\text { psi } \\
\end{array}$ & $\begin{array}{l}\text { Outside Diameter } \\
\text { in. } \\
\end{array}$ & $\begin{array}{c}\text { Wal1 Thickness } \\
\text { in. }\end{array}$ \\
\hline Hastelloy S & 42,000 & 4.179 & 0.927 \\
\hline Hastelloy $\mathrm{C}-4$ & 48,700 & 3.655 & 0.665 \\
\hline Inconel 625 & 42,000 & 4.179 & 0.927 \\
\hline Inconel 617 & 43,000 & 4.074 & 0.875 \\
\hline
\end{tabular}

TABLE 2. Required Capsule Dimensions to Avoid Fully Plastic Condition of Capsule Wall for External Pressure of $14,500$ psi ( ID $=2.325$ in. $)$

\begin{tabular}{|c|c|c|c|}
\hline Material & $\begin{array}{c}\text { Yield Strength } \\
\text { psi } \\
\end{array}$ & $\begin{array}{c}\text { Outside Diameter } \\
\text { in. } \\
\end{array}$ & $\begin{array}{c}\text { Wal1 Thickness } \\
\text { in. } \\
\end{array}$ \\
\hline Hastelloy S & 42,000 & 3.139 & 0.407 \\
\hline Haste1 loy $\mathrm{C}-4$ & 48,700 & 3.012 & 0.343 \\
\hline Inconel 625 & 42,000 & 3.139 & 0.407 \\
\hline Inconel 617 & 43,000 & 3.117 & 0.396 \\
\hline
\end{tabular}

Hastelloy $S$ had been selected as the leading candidate for the outer capsule on the basis of its mechanical properties in the aged condition. A tentative wall thickness of $0.45 \mathrm{in}$. was selected to provide a small margin of safety over the 0.407-in. minimum wall calculated for this material. Based on available data and analyses, this value appeared to be realistic. High-pressure external pressure tests on developmental capsules of various wall thicknesses were then conducted to verify the adequacy of the tentative 0.45-in. wall thickness to sustain the design pressure of 14,500 psi. 


\section{EXPERIMENTAL EVALUATION OF EXTERNAL PRESSURE CAPABILITY}

External pressure tests were performed for a set of AISI-1018 carbon steel capsules. The purpose of these tests was to establish an empirical relationship between wall thickness and external pressure capability. The AISI-1018 low carbon steel was selected as a stand-in for the Hastelloy S alloy in an aged condition. Both materials have yield strengths of about 40,000 psi. Because the low carbon steel should strain-harden at a lower rate than Hastelloy $S$, the pressure test results provide a conservative basis in this regard for the wall thickness determination.

\section{MATERIAL CHARACTERIZATION}

Test capsules were fabricated of AISI-1018 commercial steel tubing. The tubing was purchased with a finished inside diameter of $2.375 \mathrm{in}$. and an outside diameter of $3.750 \mathrm{in}$. Final outside diameters of the test capsules were obtained by machining to size. The end caps were also of AISI-1081 steel, but of a different heat than the tubing material.

The fabrication process for the tubing was not known. Such tubing would, however, be typically extruded and/or pierced. All material used in capsule pressure tests and mechanical property tests was annealed at $1500^{\circ} \mathrm{F}$ for 1 hour and furnace-cooled. No chemical analyses or metallographic characterization were performed.

Figure 5 shows the result of a tensile test performed at PNL, which gives a representative tensile stress-strain curve for the steel tubing used. Yield strengths in tension and compression are given in Table 3. Two tensile yield strengths are given; both specimens were given the same nominal annealing treatment. Tensile strengths were determined using specimens cut to measure properties in the longitudinal direction of the capsule. The second test specimen was cut from the 0.6-in. wall test capsule after external pressure testing had caused some plastic deformation (on the order of $4 \%$ ). 


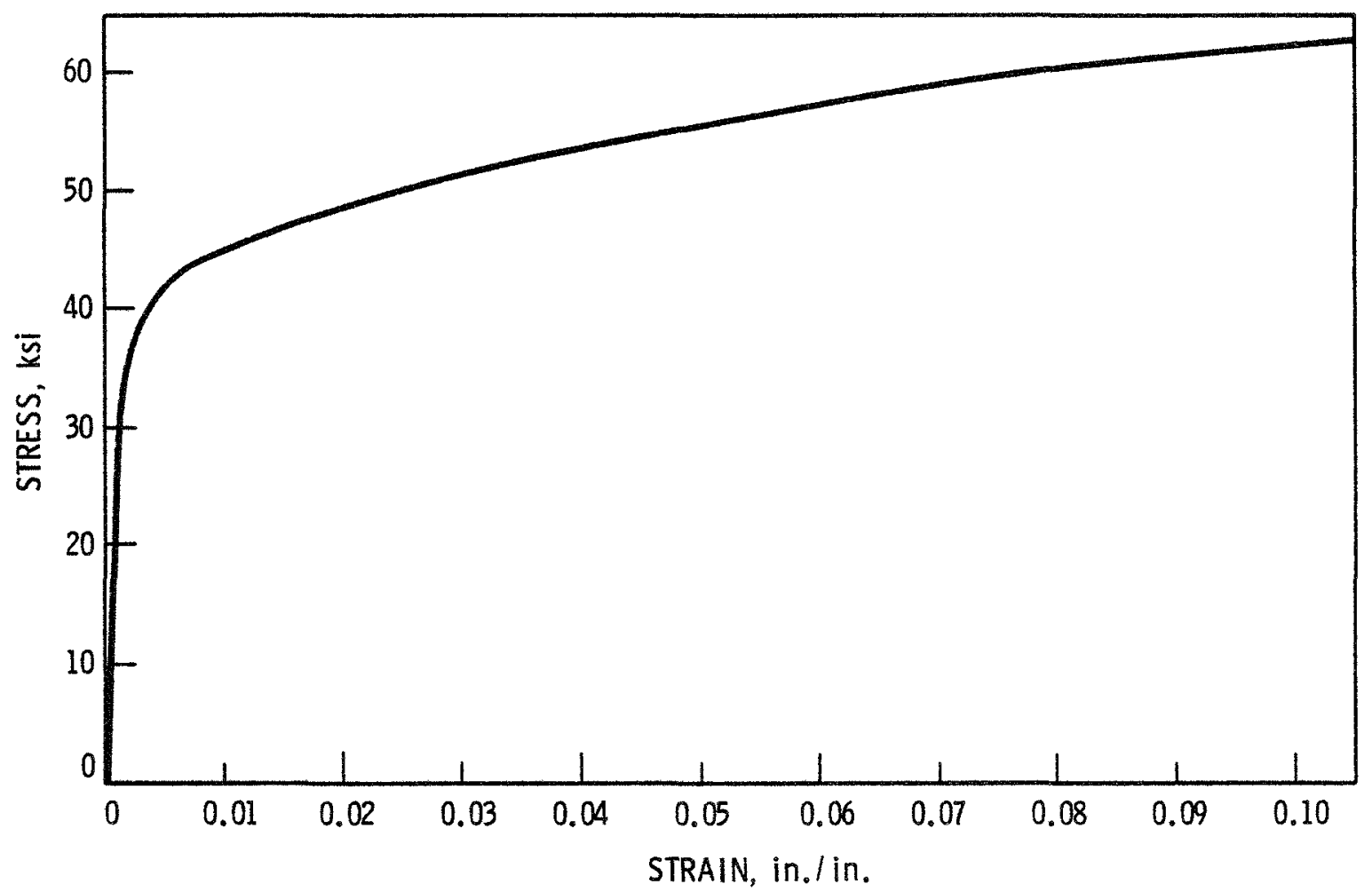

FIGURE 5. Tensile Stress-Strain Curve for AISI-1018 Carbon Steel Tubing

TABLE 3. Yield Strengths of AISI-1018 Carbon Steel Tubing Material

Yield Strength, psi

Longitudina? Circumferentia] Radial

Tension Test - Annealed

Sample of Tubing

41,350

$-$

$-$

Tension Test - 0.6-in. Wa11

Capsule

40,400

Compression Tests - 0.6-in. Wal1 Capsule

37,800

39,400

33,900 
Three miniature compression test specimens were cut from the 0.6-in. wall test capsule to measure directional yield strengths. Specimen dimensions were $0.5 \mathrm{in}$. long by $0.2 \mathrm{in.}$ in diameter. Table 3 lists yield strengths in the longitudinal, circumferential, and radial directions of the tubing material. Except for the radial compressive yield strength of 33,900 psi, the compressive strengths were comparable to the measured longitudinal tensile strength. The yield strengths may have been affected by the previous plastic deformation of capsule material in the external pressure test. However, this effect is thought to be minimal for the compression specimens because they were cut from the capsule wall near the end caps, where restraining effects of the ends essentially prevented plastic deformation of the wall.

\section{TEST PROCEDURE}

Test capsules as shown in Figures 6 and 7 were fabricated from AISI1018 carbon steel. Three capsule wall thicknesses $(0.4,0.5$, and 0.6 in.) with common inside diameters of $2.375 \mathrm{in}$. were tested. A penetration with high-pressure tubing was made in the end cap to permit introducing a pressurized gas into the capsule for leak checking between pressurizations.

External pressure tests were performed at the Civil Engineering Laboratory, U.S. Naval Construction Battalion Center, Port Hueneme, California. A 9-in. diameter by 43-in. long hydrostatic pressure chamber with a rated pressure capability of 20,000 psi was pressurized with water at room temperature. Pressures were monitored and recorded from two independent pressure gages. All tests were conducted in the presence of PNL staff.

Each capsule was pressurized in 1000-psi increments starting at 10,000 psi. After each pressurization, the capsules were removed from the vessel and the permanent diameter changes were measured using a micrometer. Diameters were measured at $45^{\circ}$ increments to observe the onset of ovalization of the capsule cross sections. The pressure was increased incrementally to 20,000 psi or until the capsules experienced total collapse in the form of flattening. 


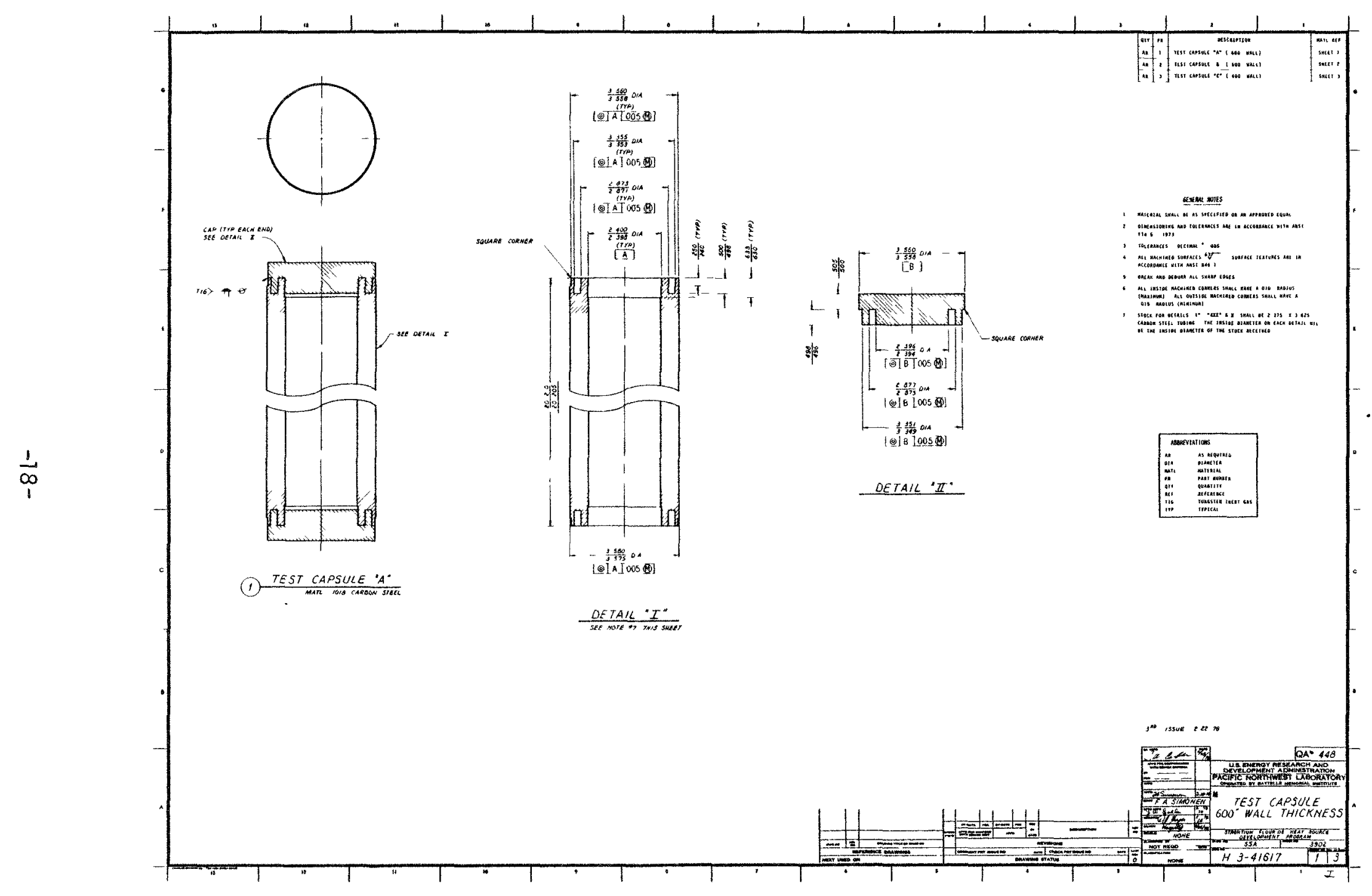

FIGURE 6. Pressure Test Capsule 


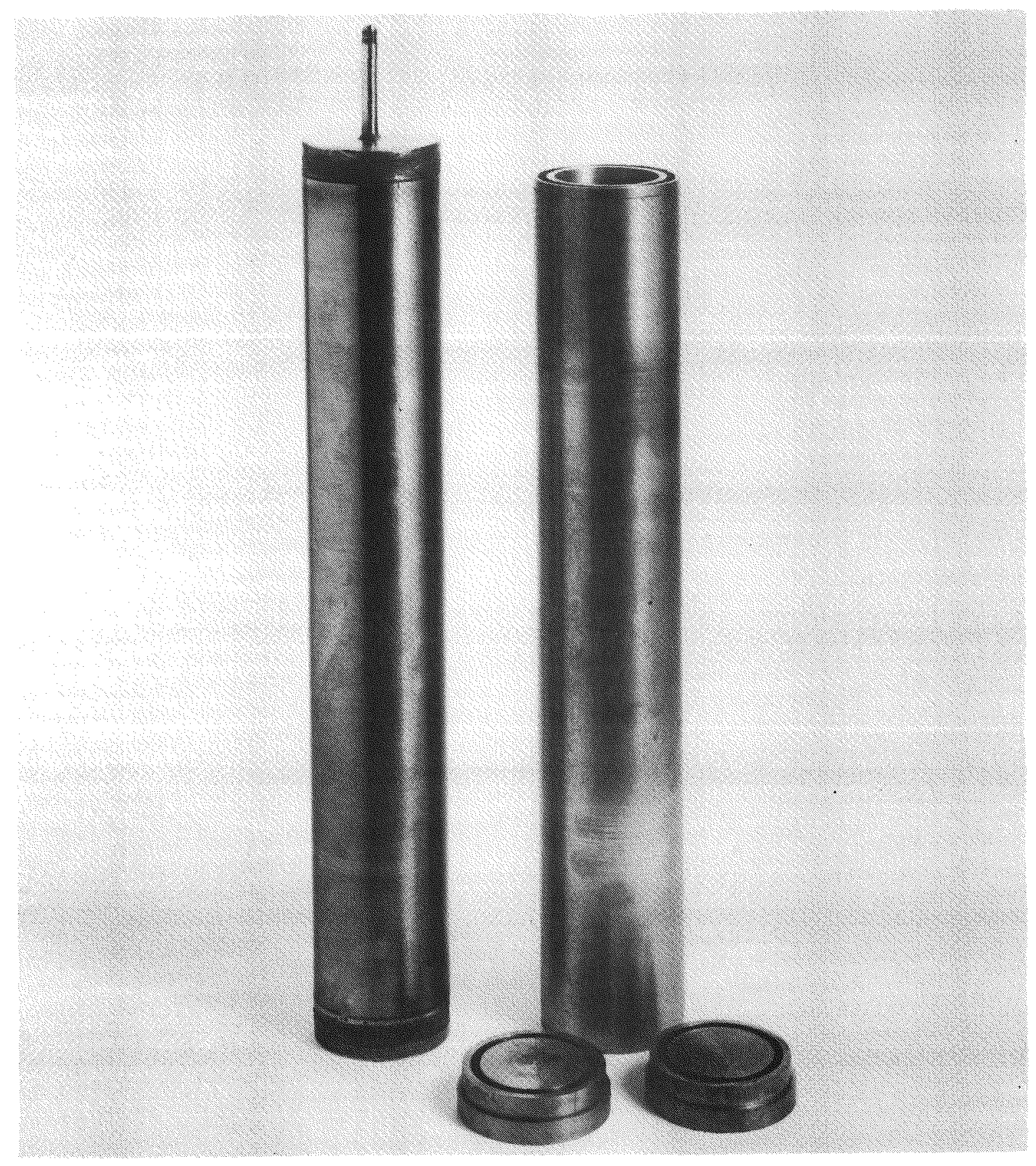

FIGURE 7. Outer Capsule Components and Completed AISI-1018 Steel Outer Capsule Ready for External Pressure Testing 
Al1 capsules were checked after testing with a helium system capable of detecting leaks of less than $1 \times 10^{-8} \mathrm{cc} / \mathrm{sec}$. No leaks were detected.

\section{RESULTS OF CAPSULE PRESSURE TESTS}

The capsules after external pressure testing are shown in Figure 8. An electrochemically etched grid used to measure external surface strains is visible on the capsule surfaces.

Maximum and minimum diameters of the capsules were measured at 1000-psi increments in pressure using a micrometer. Figures 9 and 10 show the measured average diameter change and the differential diameter change (a measure of ovalization).

A permanent average diameter change of $0.010 \mathrm{in}$. was selected as the criterion for full yielding of the capsule wal1. This level of deformation was well above the yield strain (yield strength/elastic modulus) for the material, and was consistent with trends of finite element calculations for full yielding in the capsule wall.

Figure 10 shows that the ovalization developed gradually with increasing pressure. In the final collapse, complete flattening of the circular cross section occurred with opposite sides of the capsule coming into contact. The 0.6-in. wall did not ful7y flatten at the 20,000-psi maximum pressure rating of the test vessel. The collapse pressure of 20,500 was estimated on the basis of the trend of the ovalization curve. For the two thinner capsules, collapse was noted during the test by a sudden drop in the pressure gage readings; the pumping apparatus could not sustain pressure while the capsule volume decreased. The 0.4-in. capsule collapsed violently. A sharp metallic sound was heard as the sides of the capsule impacted. Collapse of the 0.5-in. wall capsule proceeded in a more stable manner.

Table 4 and Figure 11 give the experimental pressures for both a fully plastic wall and for catastrophic collapse as a function of wal1 thickness. Both pressures, as expected, increased with increasing wall thickness. Furthermore, the margin between full-wall plasticity and catastrophic collapse showed a particularly significant increase with wall thicknesses. 


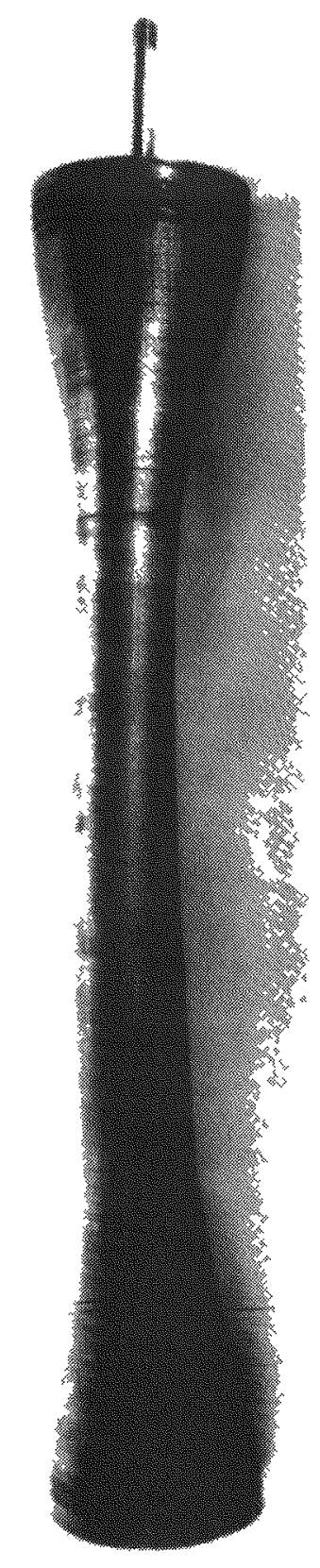

$$
\begin{gathered}
0.4-\text { Inch wall } \\
11,200 \text { psi }
\end{gathered}
$$

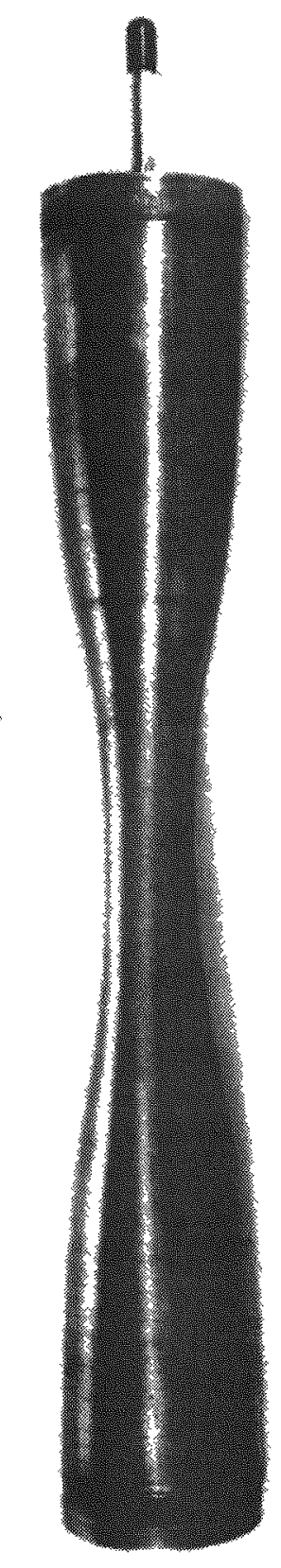
0.5 -Inch Wa 17
15,900 psi

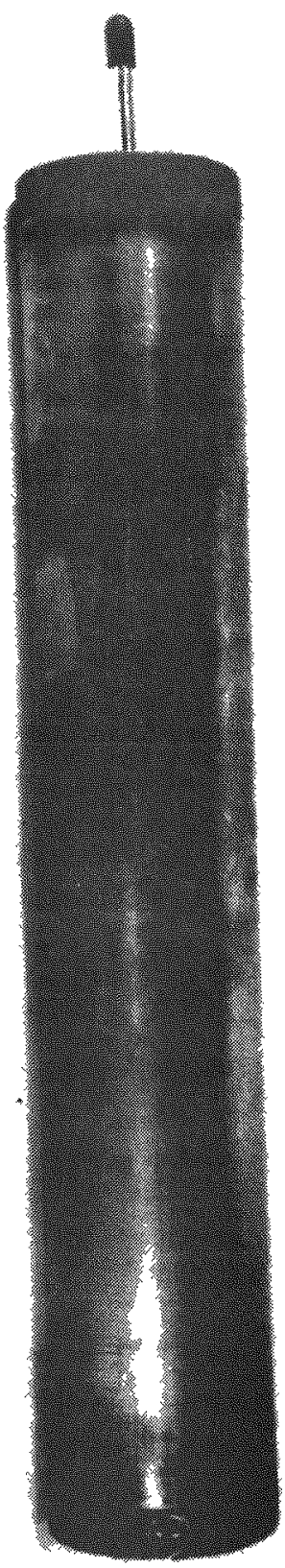

0.6-Inch Wal1 20,000 psi

FIGURE 8. Steel Capsules After Pressure Testing 


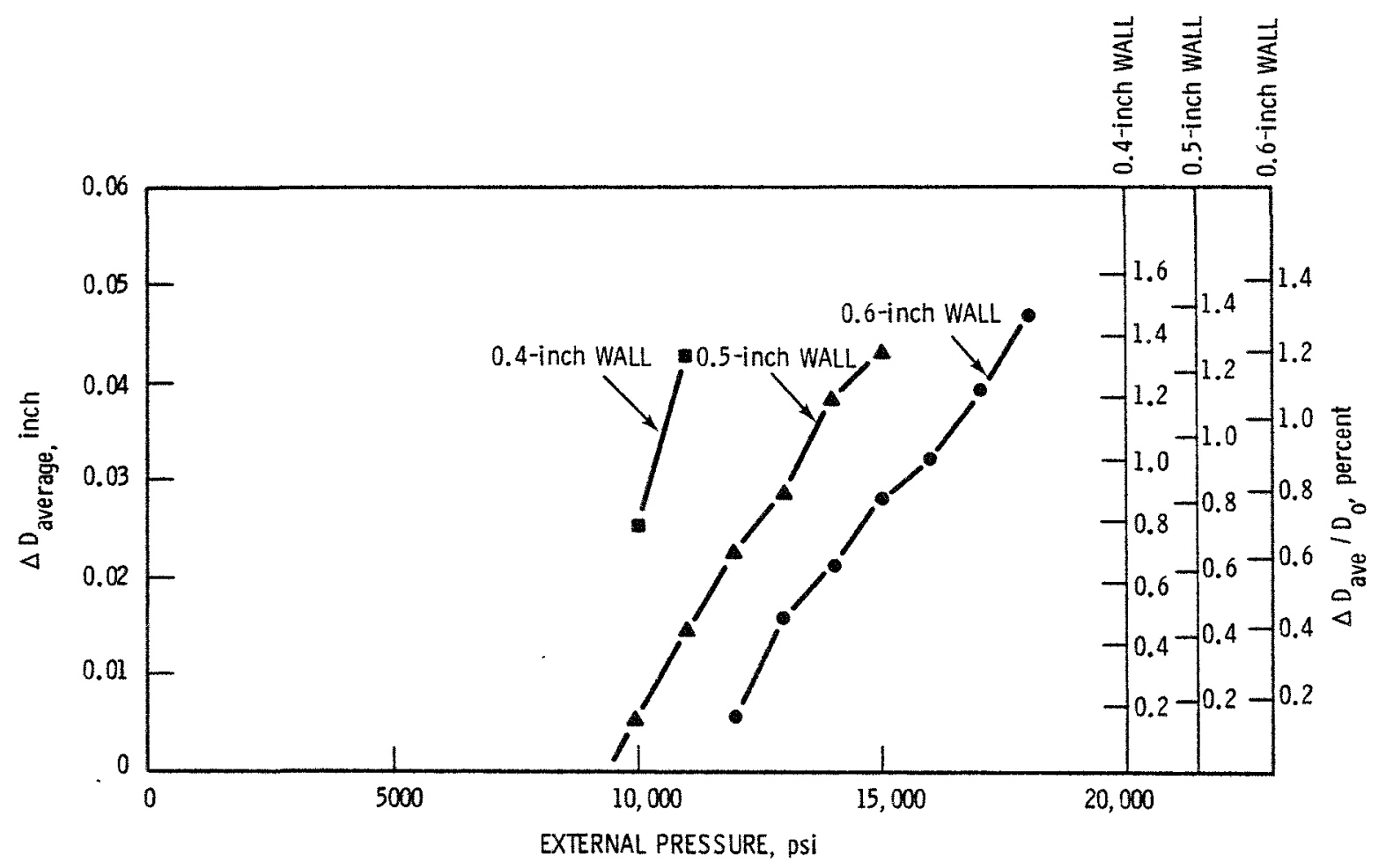

FIGURE 9. Measured Average Diameter Changes in AISI-1018 Steel Test Capsules

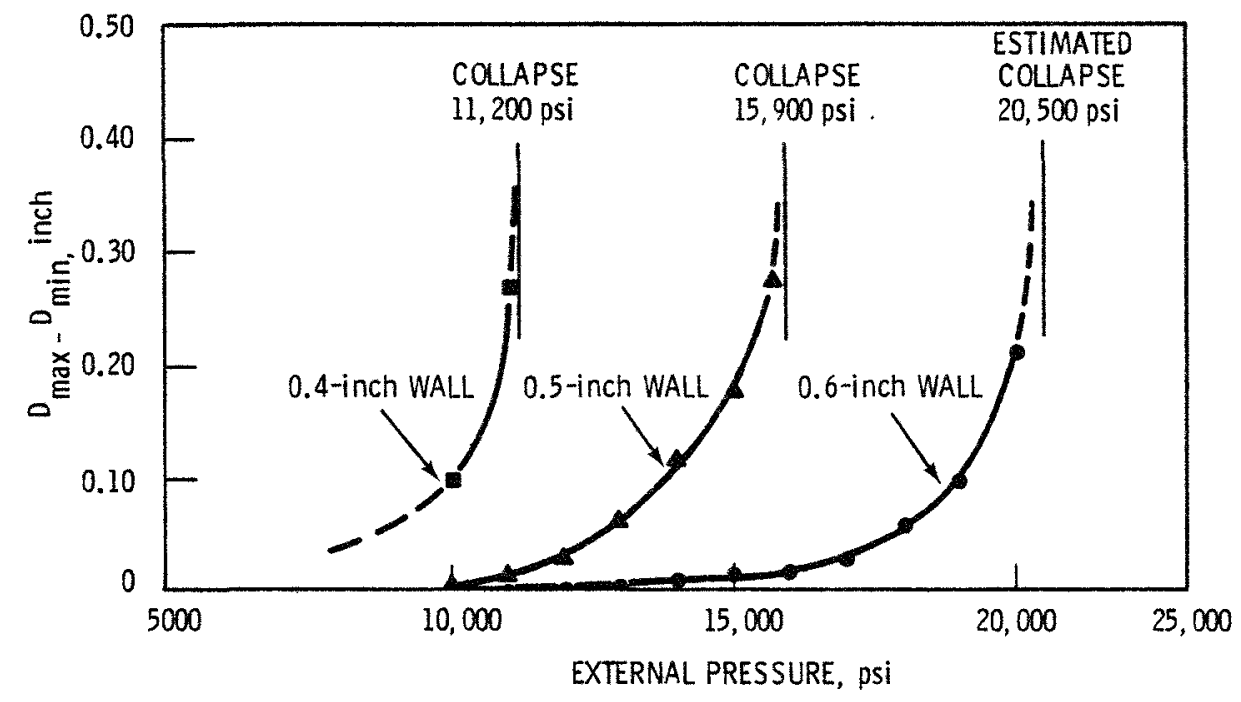
FIGURE 10. Measured Ovalization $\left(D_{\max }-D_{\min }\right)$ in AISI-1018 Stee1
Test Capsules 
TABLE 4. Capsule Dimensions and Experimental

Failure Pressures

\begin{tabular}{|c|c|c|c|}
\hline & $\begin{array}{c}0.4-I n \\
\text { Wa } 11 \\
\end{array}$ & $\begin{array}{c}0.5-\text { In. } \\
\text { WaI1 }\end{array}$ & $\begin{array}{c}0.6-\text { In. } \\
\text { Wa11 }\end{array}$ \\
\hline Inside Diameter, in. & 2.375 & 2.375 & 2.375 \\
\hline Outside Diameter, in. & 3.175 & 3.375 & 3.575 \\
\hline $\begin{array}{l}\text { Measured Bore Eccentricity, } \\
\text { in. }\end{array}$ & 0.005 & 0.011 & 0.0045 \\
\hline $\begin{array}{l}\text { Pressure for Fully Plastic } \\
\text { Wall of Capsule, psi }\end{array}$ & 9,000 & 10,500 & 12,500 \\
\hline $\begin{array}{l}\text { Pressure for Collapse (Cat- } \\
\text { astrophic Ovalization), } \\
\text { psi }\end{array}$ & 11,200 & 15,900 & 20,500 \\
\hline
\end{tabular}

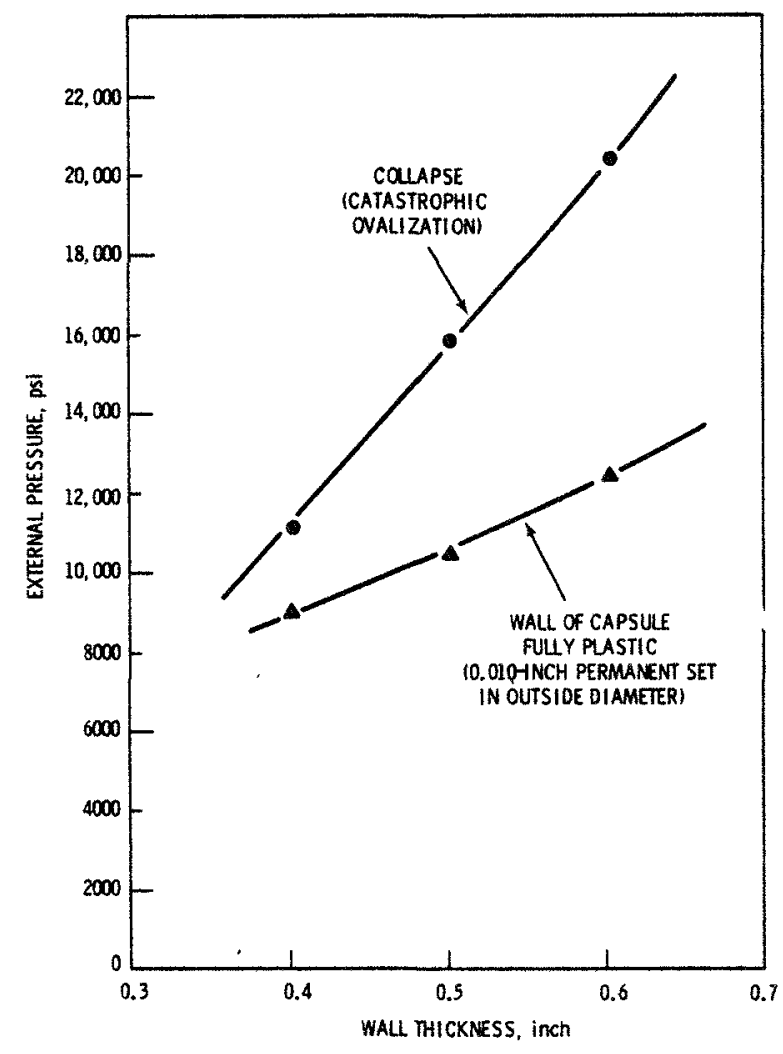

FIGURE 11. Experimental Yield and Collapse Pressures for AISI-1018 Steel Test Capsules 
Thus, the thicker-walled capsules had a disproportionately enhanced resistance to ovalization.

Figure 12 shows strain data obtained from the electrochemicaliy etched grids on the outside surface of the 0.5-in. wall capsule. Changes in the etched 0.1-in. diameter circles were measured on a circumferential trace and along two longitudinal lines. As indicated, axial strains were small compared to the measured hoop strains. Compressive strains were as high as $50 \%$ while tensile strains showed a peak of 30\%. No cracks were observed in the AISI-1018 steel capsules in visual checks, and no leaks were detected in the helium leak tests. However, it is probable that the ductility of Hastelloy $S$ in an aged condition would not be sufficient to prevent cracking of the capsule at the measured tensile strain levels of $30 \%$.

\section{PREDICTED VERSUS EXPERIMENTAL COLLAPSE}

Two plastic collapse pressures have been defined for the thick-walled capsules. The first corresponds to a fully plastic condition in the capsule wall. The second pressure 1 imit was for unstable ovalization and catastrophic flattening. For the capsule wall thicknesses of interest, the fully plastic condition must occur before flattening can occur. Therefore, the first priority has been placed on the ability of analysis methods to predict the fully plastic condition. This prediction should also be more straightforward and accurate than predictions of unstable ovalization.

Figure 13 shows various predictions of the pressure for gross yield of the capsule wall along with the corresponding experimental data. All predictions give higher failure pressures than those observed in the actual tests. In was initially believed that the finite element analysis would give the most realistic predictions. However, the correlation with the finite element predictions was the least satisfactory; experimental pressures were approximately $60 \%$ of the predicted pressures.

Approximate stress formulas of Equations (9) through (11) were applied in connection with different yield criteria. The von Mises yield criterion applied in this manner to average wall stresses gave pressures approximately 

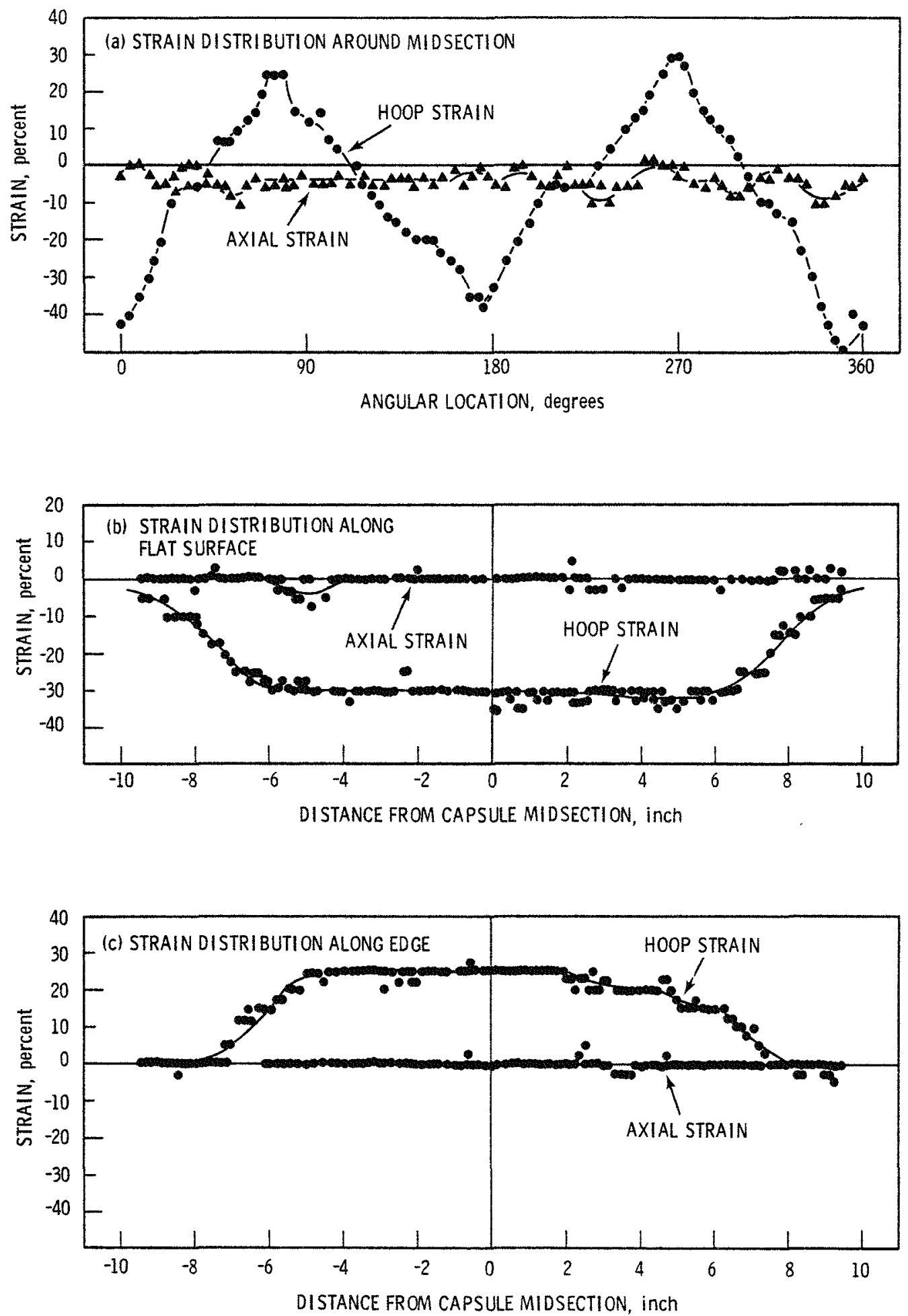

FIGURE 12. Strain Grid Data from Outer Surface of 0.5-In. Wall Capsule 


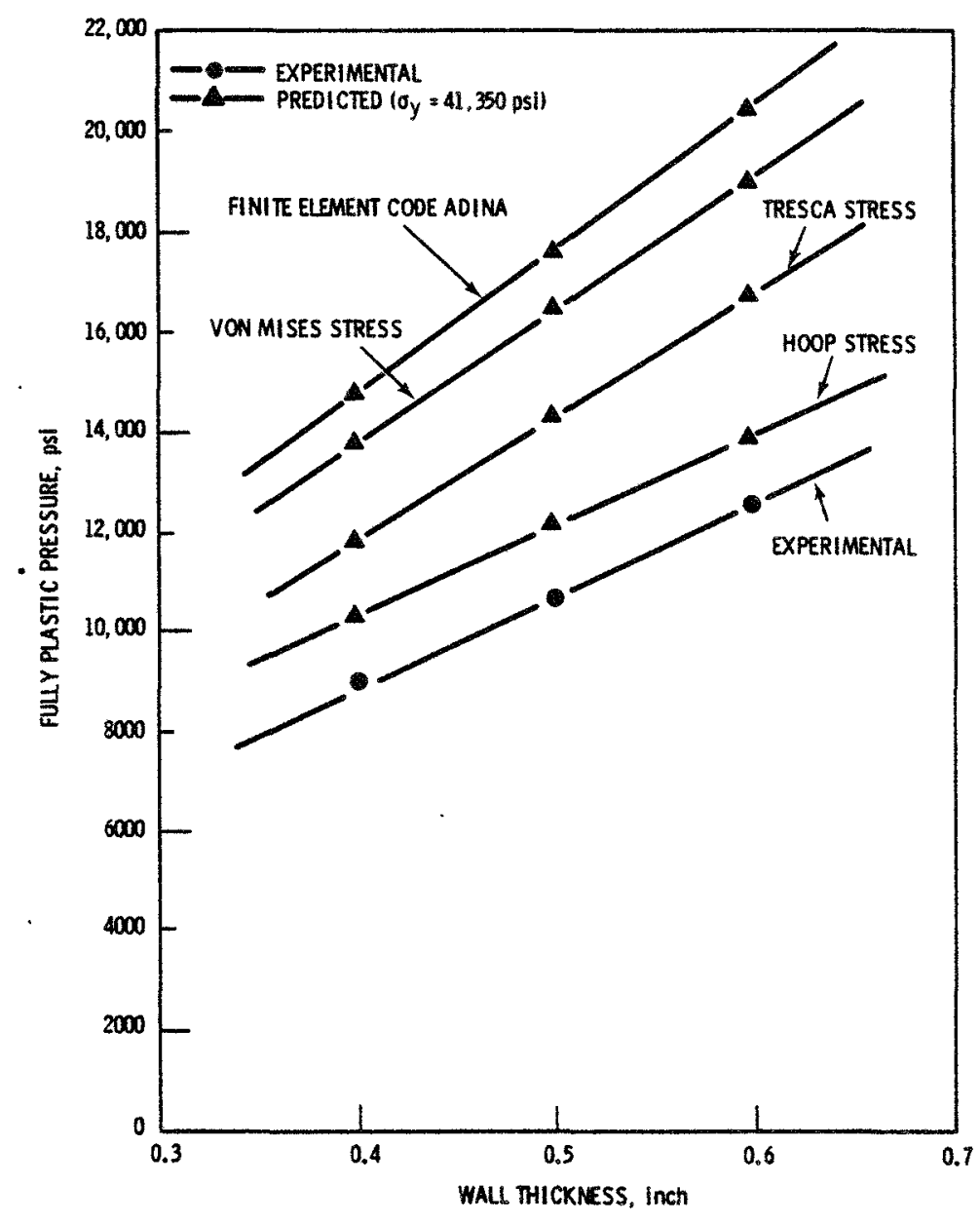

FIGURE 13. Comparison of Predicted and Measured Yield Pressures for AISI-1018 Steel Test Capsules

$6 \%$ below the corresponding finite element predictions. The Tresca (or maximum shear stress) criterion agreed better with the experimental trends, but the experimental pressures were still only roughly $75 \%$ of the failure pressures predicted by the Tresca criterion.

The final prediction assumed that yield occurred when the mean hoop stress in the capsule wall equaled the material yield strength. This method of prediction neglects the effects of the triaxial stress state in the capsule wall and is contrary to accepted theories of plasticity and the mainstream of experimental data reported in the literature. Neverthe- 
less, this prediction agrees within about $15 \%$ with the experimental data, which is within characteristic accuracy limits of plasticity theories.

The effect of directional yield strength (due to anisotropy of the tubing material as given in Table 3 ) was not considered in the correlations of Figure 13. A compressive yield of $33,900 \mathrm{psi}$ in the radial direction was the lowest yield strength measured. Because the radial stress component was the lowest of the principal stresses, this yield value should be of secondary importance relative to the overall plastic behavior of the test capsules. Nevertheless, if one arbitrarily uses the low radial yield strength in connection with the Tresca yield criterion, good agreement with the experimental data can be obtained. This suggests that a slip system related to the low radial yield strength of the AISI-1018 carbon steel may have governed capsule response.

In summary, the correlation between the experimental results and analytical predictions is disappointing. A further disturbing feature is that the correlation is better for the simplistic methods than for the more sophisticated finite element calculations. It appears that classical plasticity theory simply performs poorly for the low carbon steel capsule material under the triaxial compressive stress states present in the external pressure tests.

Both the experimental and finite element results can be nomalized with respect to the (measured or predicted) full wall yield pressure and the results can then be made to correlate quite we11. In Figures 14 and 15 , finite element results for the $0.5-i n$. wall capsule are compared with the test data. The calculations for the 0.4-in. wall were continued into the post-yield region. The finite element model included initial geometric imperfections as determined from capsule measurements. The imperfection was a nonconcentricity of the capsule bore relative to the outside diameter by an offset of $0.005 \mathrm{in}$. This offset was inferred from ultrasonic measurements of wall thickness variations. The finite element model consisted of a $180^{\circ}$ arc of the capsule cross section, which was analyzed using the plane strain option of the computer code ADINA. The total Lagrangian formulation for geometric (large deflection) effects was selected, and the external 


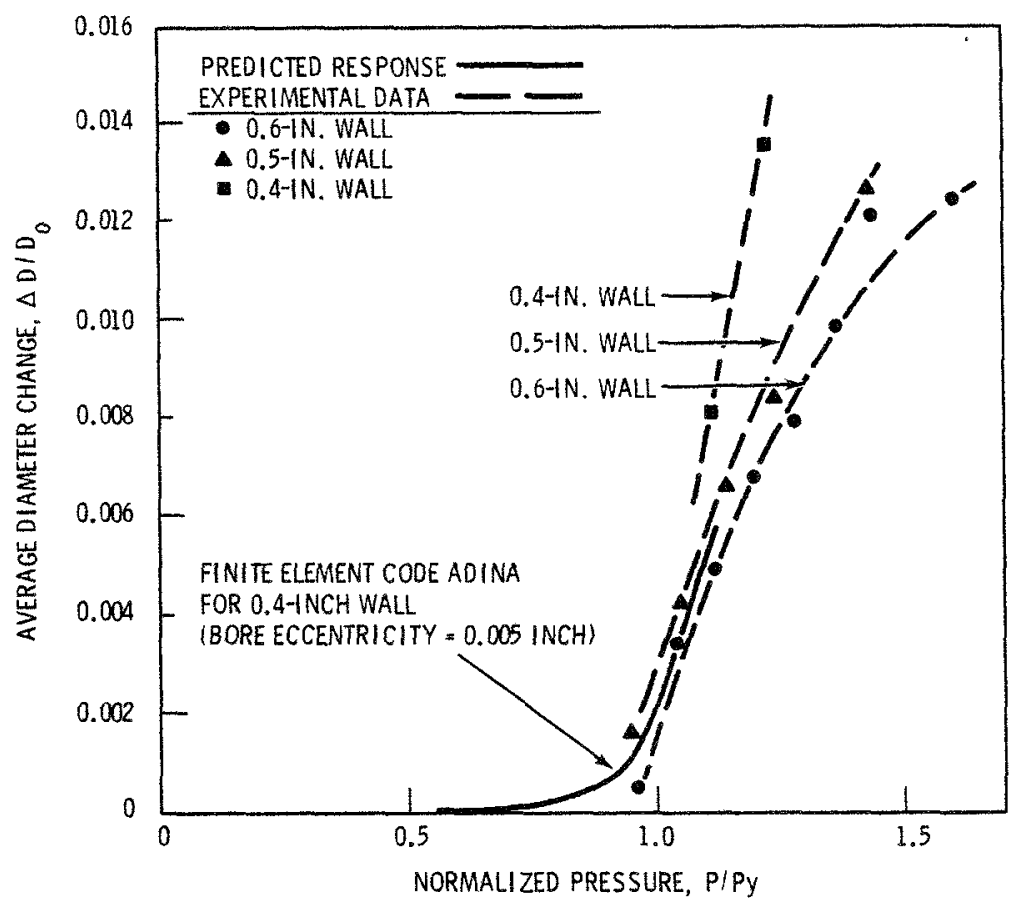

FIGURE 14. Comparison of Predicted and Measured Average Diameter Changes for AISI-1018 Steel Test Capsules

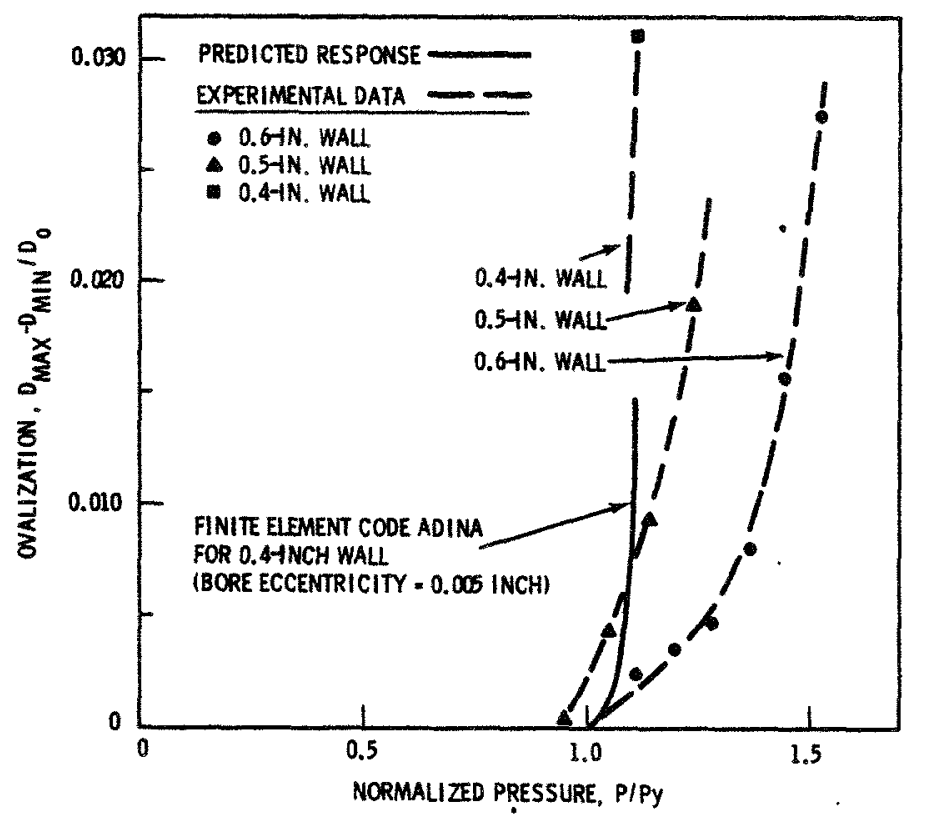

FIGURE 15. Comparison of Predicted and Measured Ovalization of AISI-1018 Steel Test Capsules 
pressure loading was applied as a "follower force" to the capsule surface. The stress-strain curve in Figure 5 was converted to a true-stress versus true-strain format, and then curve-fitted for the numerical analys is.

Figure 14 shows the predicted average diameter change as a function of pressure after normalization with respect to the calculated capsule yield pressure. In the normalized format, the predicted response falls within the scatter of the experimental data. It should be noted that the experimental data were not taken in sufficient detail to define the smooth transition between elastic and plastic behavior as exhibited by the predicted curve. Also, at the higher pressures (beyond which point the analys is was terminated), the experimental curves show a decreasing slope. This indicates the increasing ovalization that was developing in the test capsules at these pressures.

The predicted development of ovalization in the 0.4-in. wall capsule is shown in Figure 15. When plotted against normalized pressure, the predicted onset of instability agrees well with the experimental results for the $0.4-$ in. wal1 capsule. The assumed initial bore eccentricity of 0.005 in. was sufficient to initiate an unstable ovalization mode into the finite element calculations. However, as noted before, the analysis was unable to accurately predict the actual pressure for full yielding of the capsule wall $\left(P_{y}\right)$, and this delayed the predicted development of ovalization. In summary, the nonlinear finite element analysis has been shown to predict instability or ovalization in the plastic range. However, accurate prediction requires improved equations to describe yield under the types of multiaxial stress states of interest to the thick-walled capsules.

\section{POSSIBLE SOURCES OF ERROR}

A number of proposed reasons for the lack of correlation between the predicted and experimental capsule yield behavior have been evaluated. These are discussed below. 
Geometric Imperfections

It is well known that the collapse pressure of tubes under external pressure is often lowered by the presence of initial geometric imperfections, particularly initial ovalization of the ideally circular cross section. However, Heise and Esztergar (1970) show that sensitivity to imperfections decreases as the tube wall thickness to diameter ratio increases. The wall thickness ratios for the capsules tested were large and imperfections should have had little effect.

Detailed measurements of the capsules showed a small variation in wall thickness around the circumference of the tubes, which was due to eccentricities (on the order of 0.005 to $0.010 \mathrm{in}$.) of the capsule bores relative to the outside diameters. Detailed finite element calculations have included these eccentricities, and the predicted effect on capsule yield pressure was found to be negligible.

The experimental capsule behavior showed little evidence of premature ovalization due to geometric imperfections or other possible sources such as circumferential variations in mechanical properties. All capsules first clearly exhibited a period of uniform inward plastic flow, and only later began to ovalize.

\section{Anistropy}

The compression tests showed that the yield strength of the tubing material was slightly anisotropic; the radial yield strength was approximately $15 \%$ less than the circumferential yield. As discussed above, conventional theories of plastic flow in metal would suggest that this difference had only a minor effect on the capsule behavior.

\section{Instrumentation Errors}

A faulty or out-of-calibration pressure gage could have invalidated the experimental data. However, the official pressure data were recorded from a gage that had been calibrated in accordance with the prescribed practice at the Port Hueneme Civil Engineering Laboratory. In addition, a second gage was present to monitor system hydraulic pressures; the readings 
on this gage were essentially in agreement with the official gage readings.

Heat Treatment Not as Specified

The capsules and samples for mechanical property tests were annealed prior to tests. If any of the heat treatments had been omitted or done improperly, then misleading results could have been obtained. There is no reason to suspect improper heat treatment. Furthermore, test specimens, including al1 the compression specimens, were cut from one of the capsules (0.6-in. wal1) after pressure testing and the measured yield strengths were consistent with previous data.

Identification of Compression Specimens

A low compressive yield strength (i.e., low relative to strengths in the axial and circumferential directions of the tube) was measured for the radial direction of the tube. Had the low yield been in the circumferential direction, the experimental trends would have been far more consistent with the stress calculations. The possibility that the radial and circumferential specimens were switched or mislabeled in handling has been considered. This appears unlikely. Evidence shows careful recordkeeping by the machinist. The specimens were systematically labeled, and were clearly identified in subsequent handling.

End Cap Effects

The presence of end caps on the test capsules tended to prevent collapse near the ends of the capsules. If the capsules were sufficiently short, this restraining effect could increase the observed collapse pressure of the capsules. However, finite element calculations were performed to estimate the extent of end cap effects. The results indicate that the center portion of the capsules should be essentially unaffected by the end restraint. Further, any such restraint would have increased the pressure capability of capsules and improved the apparent correlation between the tests and the analytical predictions. 
Detection of Yielding in Capsules

The occurrence of yielding through the full thickness of the capsule wal1 was inferred from measurement of the capsule outside diameter. This required some arbitrariness in selecting a permanent change in outside diameter of $0.010 \mathrm{in}$. as the criterion for full plasticity. The selected criterion did, however, correlate with the rapid decrease in capsule diameter with increasing pressure. It was also consistent with the events associated with full wall plasticity in the analytical studies. Nevertheless, there could be some error, perhaps $5 \%$, in terms of pressure in defining the occurrence of fully plastic behavior in the test capsules. Residual Stresses

The presence of residual stresses in the walls of the capsules could affect the capsule behavior. However, these stresses were probably quite low due to the annealing of the capsules prior to testing. Furthermore, while residual stress could affect the first occurrence of local yielding, they should have little effect once full plasticity develops in the capsule wa11.

\section{Yield Criteria}

The yield criteria used in plasticity theories for the plastic behavior of metals have been shown to reasonably approximate various experimental observations. However, for biaxial stress states, errors on the order of $15 \%$ are not considered unusual. Furthermore, data for triaxial stress states, such as were present in the test capsules, are very 1 imited. For the particular AISI-1018 low carbon steel thick-wall tubing, no data were available to evaluate the accuracy of conventional yield criteria. The results of the capsule tests evidently show that existing yield criteria can be in considerable error. The lack of agreement between analyses and experiment in this study is attributed mainly to the inadequacy of the plasticity theories used in the analysis. 


\section{Discussion}

Yield and plastic flow in metals under multiaxial stresses in various loading histories has been the subject of extensive study in the literature. Therefore, data were sought for the materials and stress states relevant to the capsule tests.

Nadai (1950) summarizes much of the classical work on the subject of plastic flow in metals. Mechanical test data generally show agreement with analytical predictions using conventional plasticity theories. Such theories assume that the hydrostatic component of stress does not contribute to plastic deformation, al though generalized theories have been formulated that include a pressure dependence of yield. However, experimental data for triaxial stress states are so 1 imited that such theories are largely undeveloped except as mathematical concepts.

Gupta (1977) reports a pressure dependence of yield in high-strength steels. However, the effect was small relative to the discrepancies seen in the present study. Also, unlike the present study, Gupta's data showed an apparent increase in yield strength with increasing hydrostatic pressure.

Two isolated test results have been noted in which tubing has evidently sustained plastic collapse at lower pressures than predicted. However, the original references were not available to the authors and details of the tests and the significance of the reported trends could not be evaluated. In tests of 011 well casings, Edwards and Mi1ler (1939) obtained an isolated failure well below expected stress levels. The error in prediction was comparable to that for the present capsule study. Llorens (1977) has analyzed compression data for thick-walled tubes from the classical experiments of Bridgeman (1952) and found that theoretical results overestimated the strength of the tubes in question. However, details of the experimental conditions and materials involved were insufficient to draw any general conclusions.

Michno and Findley (1975) have conducted extensive experiments on SAE-1017 steel. All data were generated for biaxial stress states. The data show marked changes in the yield surface due to previous plastic 
deformation (kinematic hardening). Such effects apparently were not important in capsule behavior, because the measured tensile and compressive strengths were comparable. In Michno and Findley's work, the initial yield surfaces for biaxial stress generally fit the von Mises yield criterion. However, no triaxial data were presented. 


\section{END CLOSURE CONFIGURATION DETERMINATION}

The 30-ft drop impact requirement was the primary consideration in the design of the end closure. Maximum damage will occur for a drop onto the corner of the capsule in an orientation such that the capsule's center of gravity is in line with the direction of travel and the impact point. Such an impact will maximize the deformation of the closure weld.

\section{REVIEW OF CLOSURE CONCEPTS}

Traditional1y, designing capsules for impact has been based largely on empirical test results. In the PNL development program, published results on capsule performance were reviewed for insights into preferred closure design concepts. Both threaded and unthreaded closures have been employed, along with tungsten inert gas (TIG) and electron beam welding. Figure 16 from Grove et a1. (1965) shows typical closure methods. Figure 17 shows the effects of impact on these closure designs as evaluated in the Kilowatt Isotope Program at Oak Ridge National Laboratory (Bradley 1973). A corner impact has resulted in a rotation of the joint and an opening up of the partial penetration closure weld for both designs. With the greater depth of penetration of the electron-beam weld, rupture that occurred for the TIG weld was avoided. The general lack of resistance of partial penetration welds to impact loadings is described by Shappert (1970).

A full penetration weld was preferred for sealing the capsule. However, for the remote welding environment in a hot cel1, the production of a full penetration weld presents practical difficulties. Use of filler metal, for example, is difficult. The end closure used in the current WESF outer capsule shown in Figure 1 incorporates a complete penetration with no filler wire weld. The weld joint is subject to severe bending stresses associated with local buckling of the capsule wall under end impact conditions, due to the relatively thin capsule wall. According to Hammond (1975), impact tests of the existing WESF capsule have not yet resulted in failure of this full penetration weld. However, the capsule material used in these tests was 


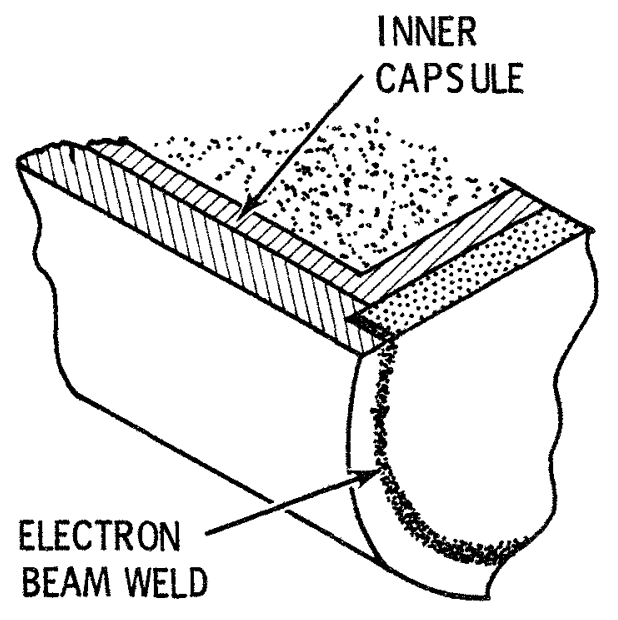

SNAP-15A FUEL CAPSULE

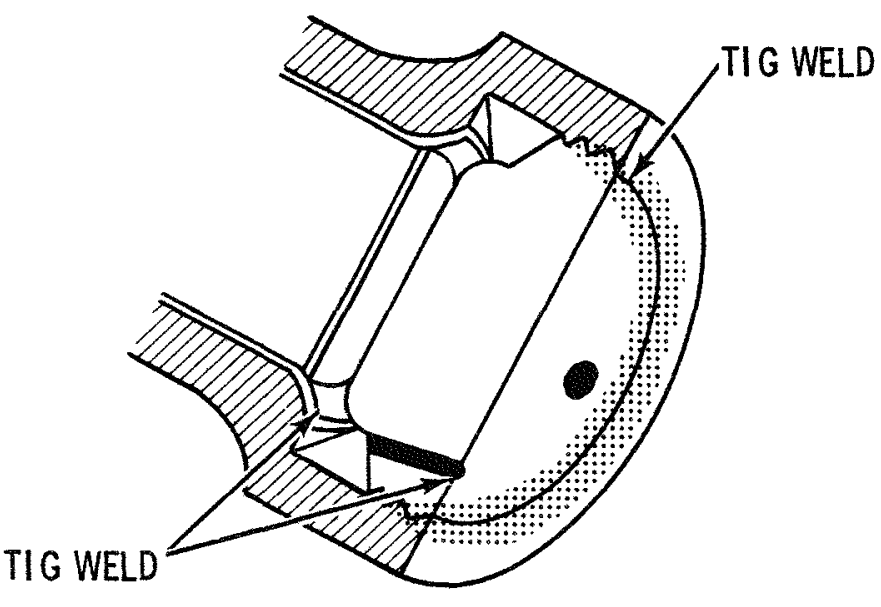

SNAP-3 FUEL CAPSULE

FIGURE 16. Typical Capsule Closure Concepts (Grove et a1. 1965)

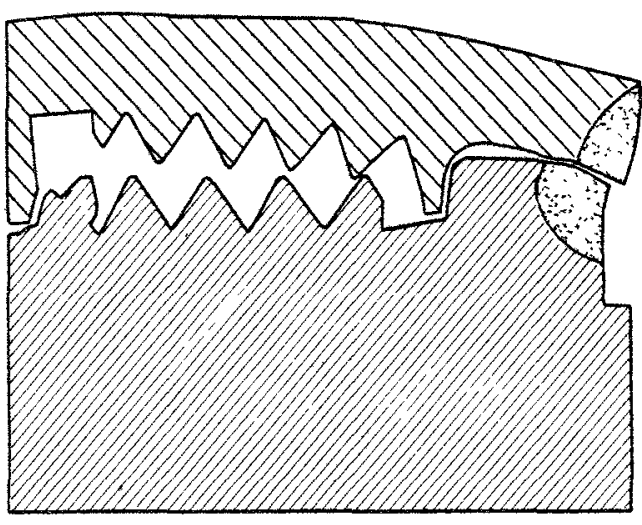

PLASMA ARC WELD

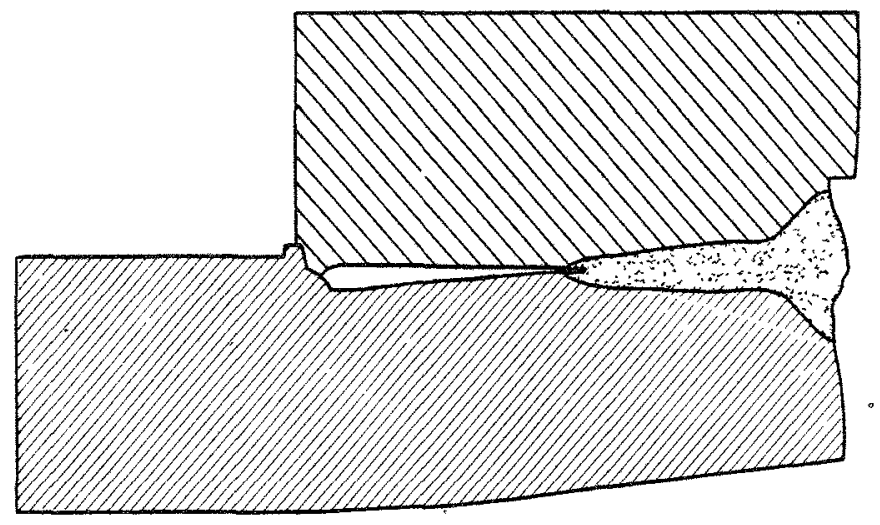

ELECTRON BEAM WELD

FIGURE 17. Effect of Corner Impact on Closure Welds 
316L stainless steel and was not embrittled, as will be the case for the Hastelloy $S$ material of the heat source outer capsule after long-term aging in service.

The proposed end closure design and seal weld configuration for the outer capsule are shown in Figures 6 and 18. This design preserves the ful 1 penetration heat source weld configuration of the present WESF outer capsule with no increase in weld penetration depth. The 0.1-in. penetration depth is close to the limit for TIG welding of the joint without the use of filler metal. Figure 18 shows a welded end closure at each end of the outer capsule. Another option is to integrate one end with the capsule, eliminating the need for a second welded closure. The integral end could be achieved by machining the capsule from solid bar stock.

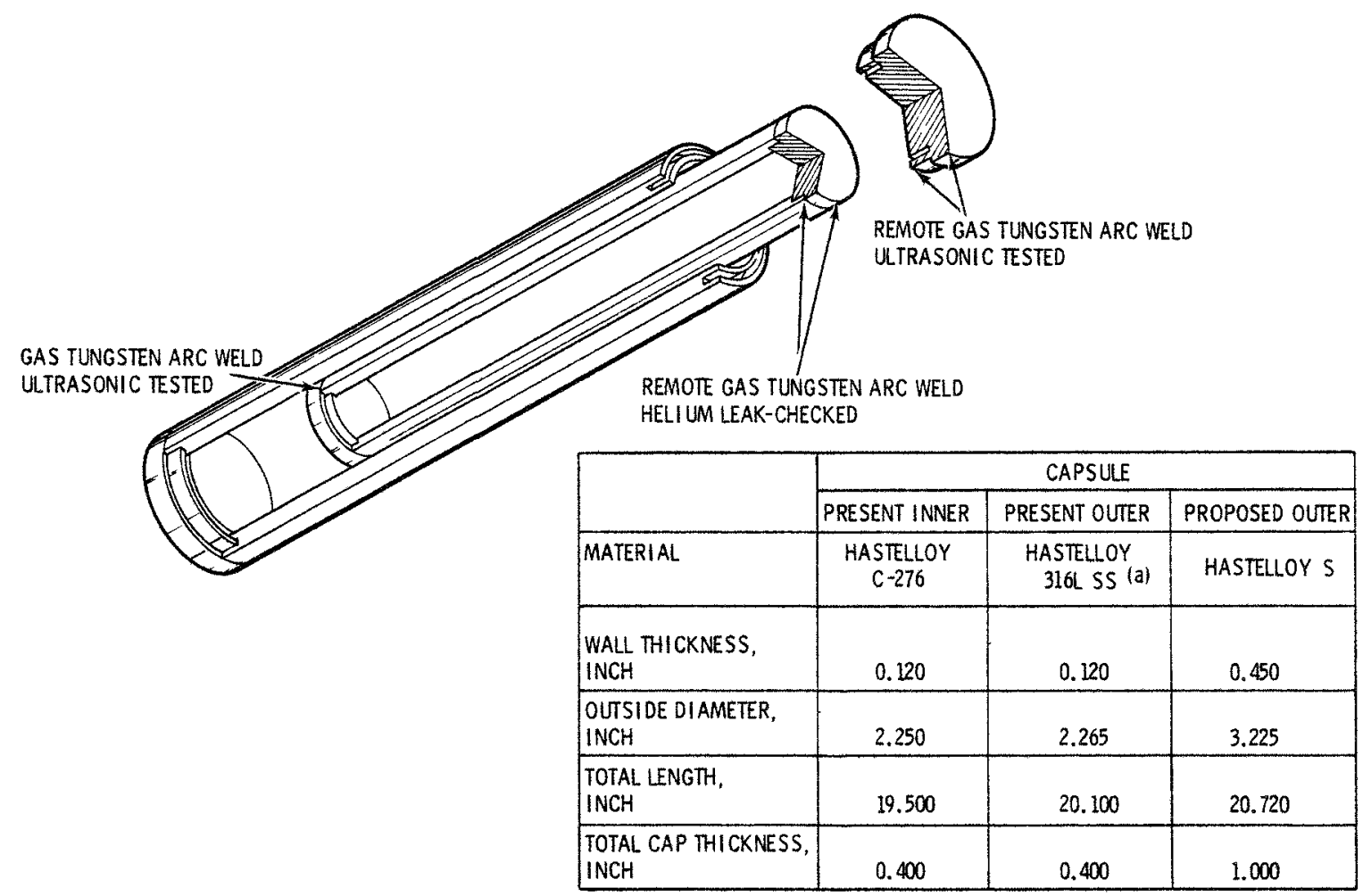

(a) INITIAL OUTER CAPSULES WERE HASTELLOY C-276

FIGURE 18. Proposed Outer Capsule for Hanford Waste Encapsulation and Storage Facility Capsules 
With the increase in wa11 thickness over that for the present WESF capsule dictated by the 1000-bar hydrostatic pressure test, it was desirable to increase the mechanical strength of the joint without increasing the weld penetration depth. This increase in strength is provided by mechanical interlock, which serves to suppress local buckling deformation at the very end of the capsule. Although this interlock arrangement complicates the machining requirements, it enhances the joint strength while minimizing welding requirements. Detailed stress analyses of the performance of this joint under pressure and impact loadings are discussed below.

\section{FINITE ELEMENT END CLOSURE DESIGN IMPACT ANALYSIS}

The performance of the interlocking end closure design under impact conditions was evaluated using the finite element computer program HONDO (Key 1974). This program is applicable to axisymmetric solids and uses an explicit time integration scheme to treat deformations associated with stress wave propagation, impact, and impulsive loading. The formulation accounts for large strain plasticity and large deformation effects.

Two end closure designs were analyzed. One design followed conventional practice, for which local buckling and high weld stresses would be anticipated. This design served as a baseline for evaluating the interlocking end cap. Figure 19 shows the finite element model for the interlocking end cap design. The capsule wal1 was 0.6 in. thick. For computational economy, the model was truncated at capsule midlength and deleted portions of the capsule were represented as added mass concentrated at the capsule midlength. This procedure adequately represented the relevant portion of the capsule actually deformed in the impact.

Due to the axisymmetric nature of the HONDO code, an ideal end-on impact was simulated. It was assumed that a corner impact will result in essentially the same type of deformation pattern as the end-on impact. The corner impact will, however, focus this deformation at one side of the capsule. The target was modeled as an unyielding surface and reaction loads were applied as needed by HONDO to prevent penetration of the impact plane by the end of the capsule. Similar reaction loads were automatically 


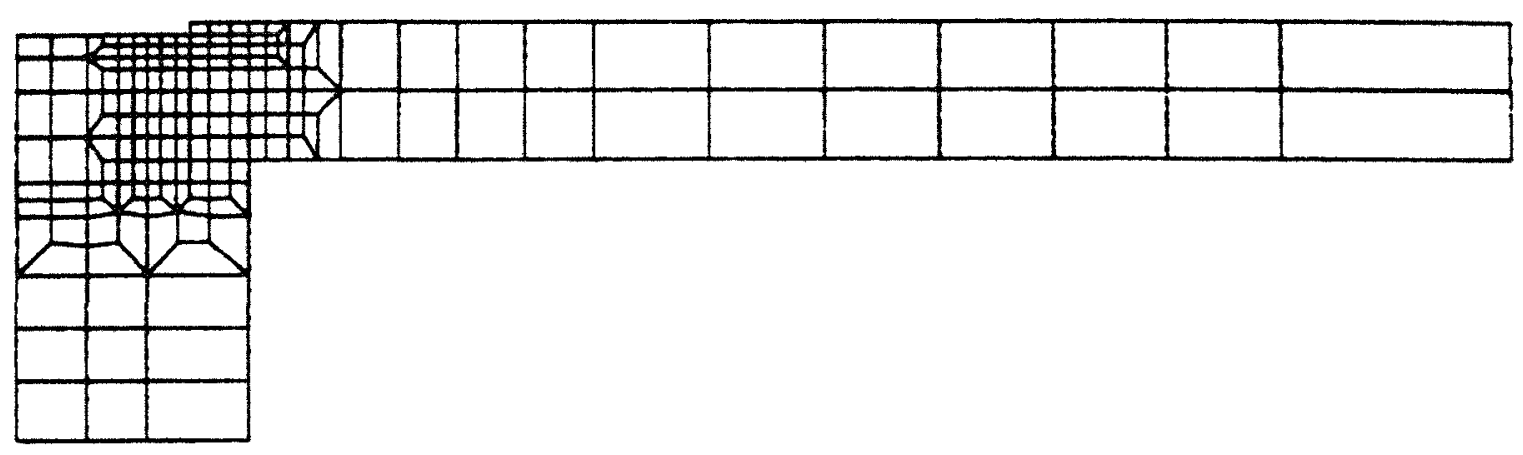

FIGURE 19. Finite Element Model for Impact Analysis of Interlocking End Cap

imposed along interfaces between the end cap and the capsule body. These loads permitted sliding and gap formation but not material penetration.

The impact velocity was $44 \mathrm{ft} / \mathrm{sec}$, corresponding to the terminal velocity of a 30-ft drop. A yield strength of 25,000 psi was assigned to the capsule material to represent Hastelloy $S$ at an elevated temperature at the time of impact. A bilinear stress-strain curve was simulated with a slope in the plastic range of $E_{t}=500,000$.

Figure 20 shows the predicted capsule deformation to actual scale for the noninterlocking end cap design. The predicted impact duration was about $561 \times 10^{-6} \mathrm{sec}$. Outward buckling of the capsule wall adjacent to the end cap was predicted, in a manner similar to that observed in impact tests of the WESF cesium chloride outer capsule as reported by Hammond (1975). Plastic strains were focused into the region of the weld and the deformation was such to open and propagate a defect in the weld due, for example, to incomplete weld penetration.

Figure 21 shows the predicted deformation for the interlocking end cap configuration. There is no localization of deformation at the weld location and the plastic deformation appears to be well-distributed into the body of the capsule. The formation of a small gap was predicted at the innermost 


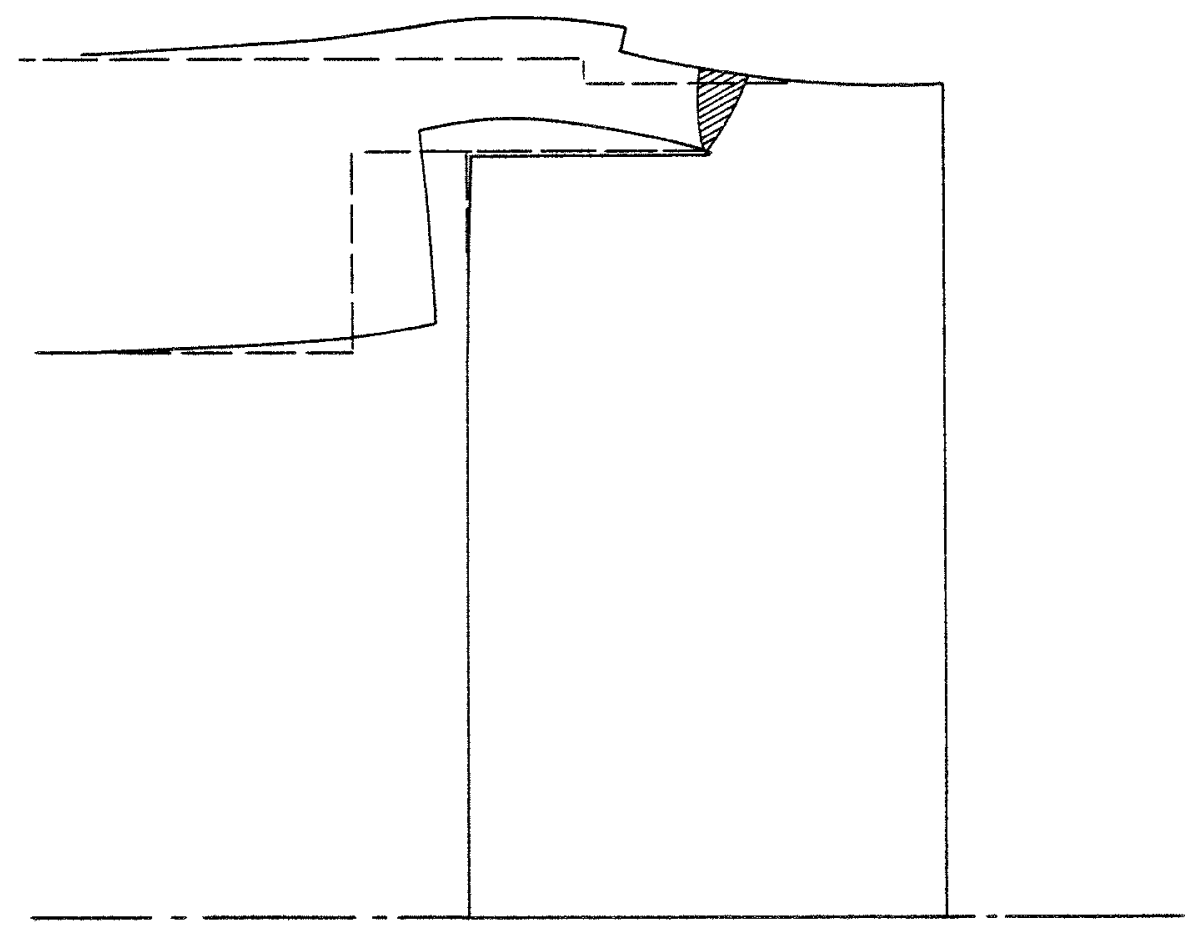

FIGURE 20. Predicted Deformation of Noninterlocking End Cap for End Impact of 30-Ft Drop

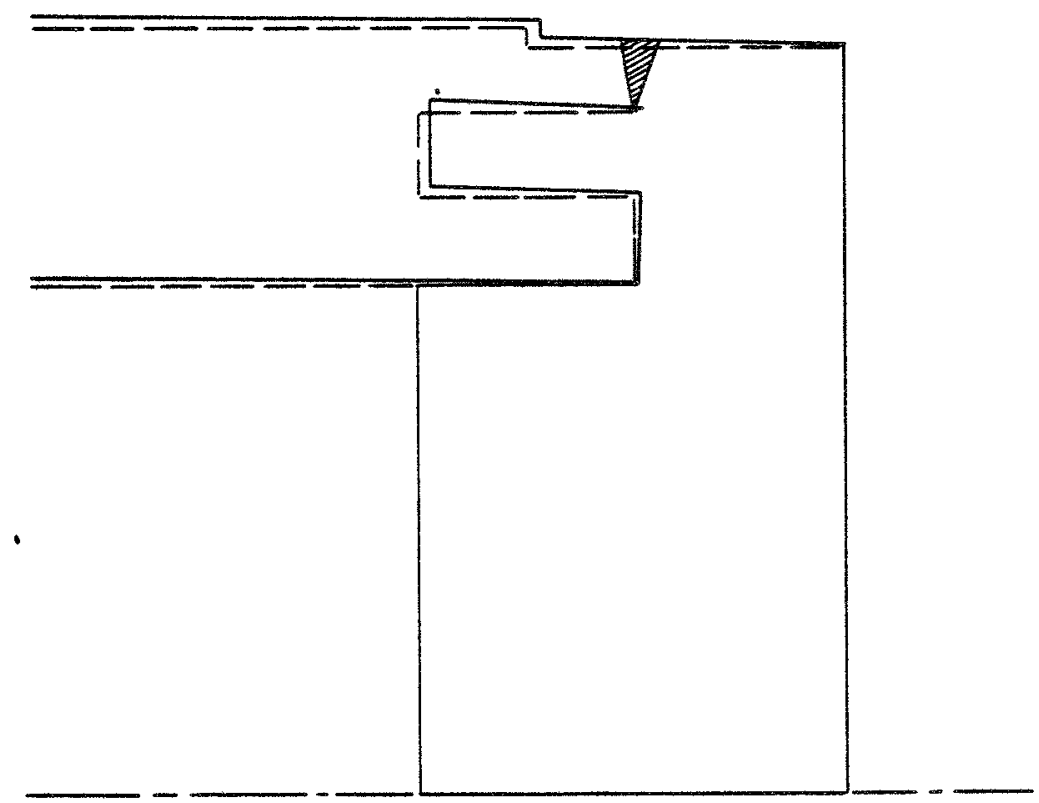

FIGURE 21. Predicted Deformation of Interlocking End Cap For End Impact of 30-Ft Drop 
interface between the end cap and the capsule wall. However, there was no tendency for opening of gaps at the weld location.

The impact calculations were intended to allow comparison of design options. Qualification tests, as reported below, were required to demonstrate the integrity of the design under end impact conditions. However, the computer simulation does show that the interlocking end cap should perform as intended, by preventing gross plastic deformation at the weld location.

\section{FINITE ELEMENT END CLOSURE DESIGN EXTERNAL PRESSURE ANALYSIS}

The computer program ADINA was used to analyze end closure stresses due to the 14,500-psi external pressure condition. Figure 22 shows the finite element model for the closure design shown in Figure 18. Predicted deflections for the symmetric half model of the capsule are shown in amplified form in Figure 23. The radial deflection at capsule midlength is $0.0015 \mathrm{in}$. The end cap deflects or bows in at the center by $0.0051 \mathrm{in}$.

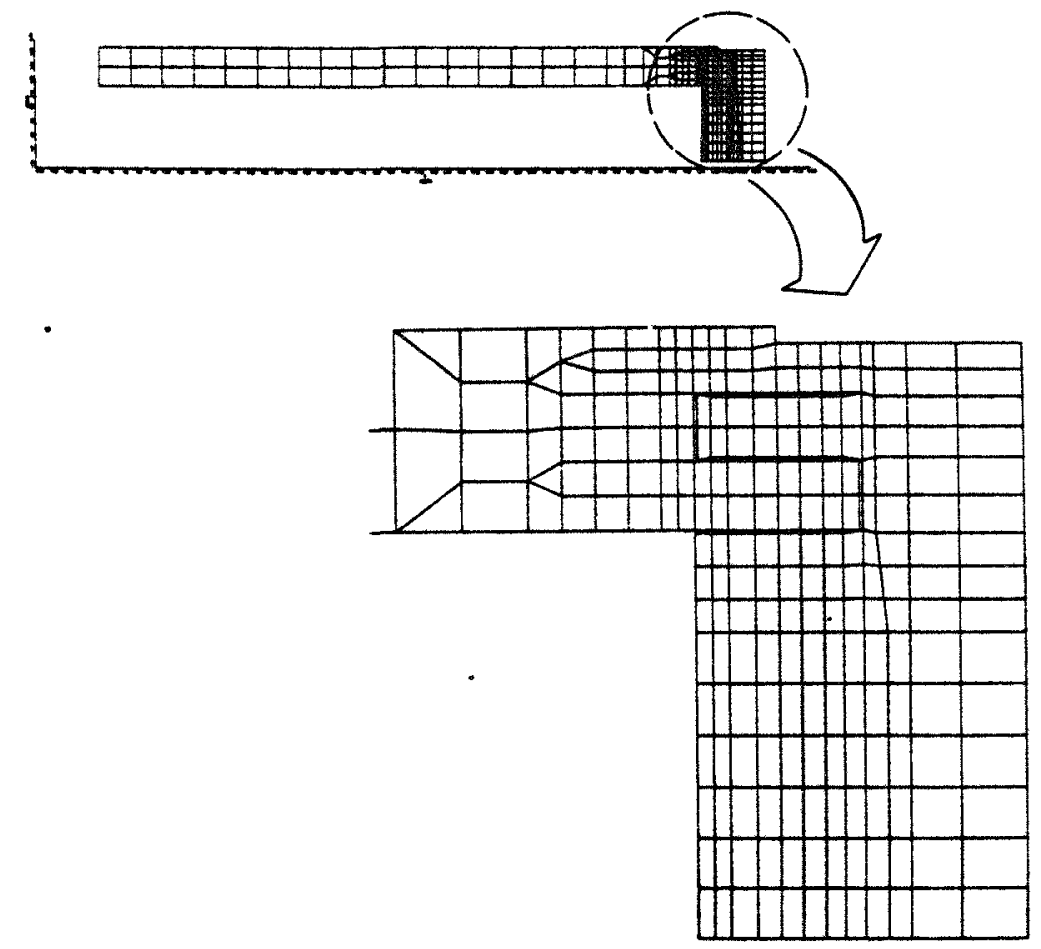

FIGURE 22. ADINA Model for Analysis of Pressure-Induced End Closure Stresses 


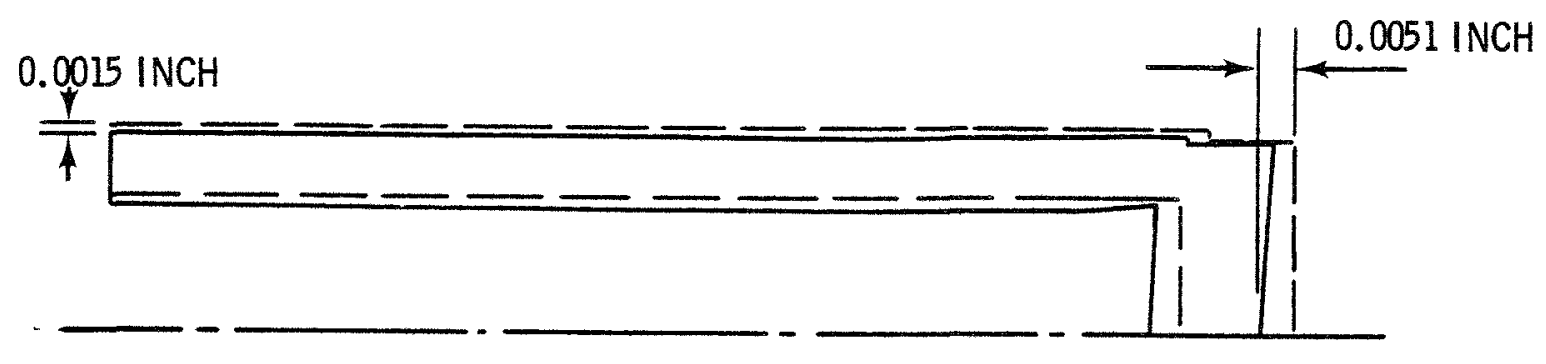

FIGURE 23. Predicted Deflection of Capsule for External Pressure of 14,500 psi $(0.6-$ In. Wa11)

The major concern in this analysis was the stresses in the final closure weld. Figure 24 shows contours of von Mises effective stress. A contour value of 42,000 psi (equal to the material yield strength) implies yielding at the particular location of concern. Only the elastic analysis portion of ADINA was used in these calculations; plastic analysis was not exercised. It can be noted in Figure 24 that stresses at the closure weld location do not exceed 10,000 psi. Hence, for the external pressure loading, the closure weld is subject to relatively modest stress levels. The elastic analysis predicts local yielding at two corner locations. These stresses are of little concern, as they are very localized and primarily compressive in nature.

It was concluded that end closure stresses for the 14,500-psi pressure of the qualification tests will not compromise capsule integrity. As was subsequently verified in the external pressure tests, the analyses showed that the center section stresses rather than closure stresses will limit the maximum pressure capability of the capsule. 


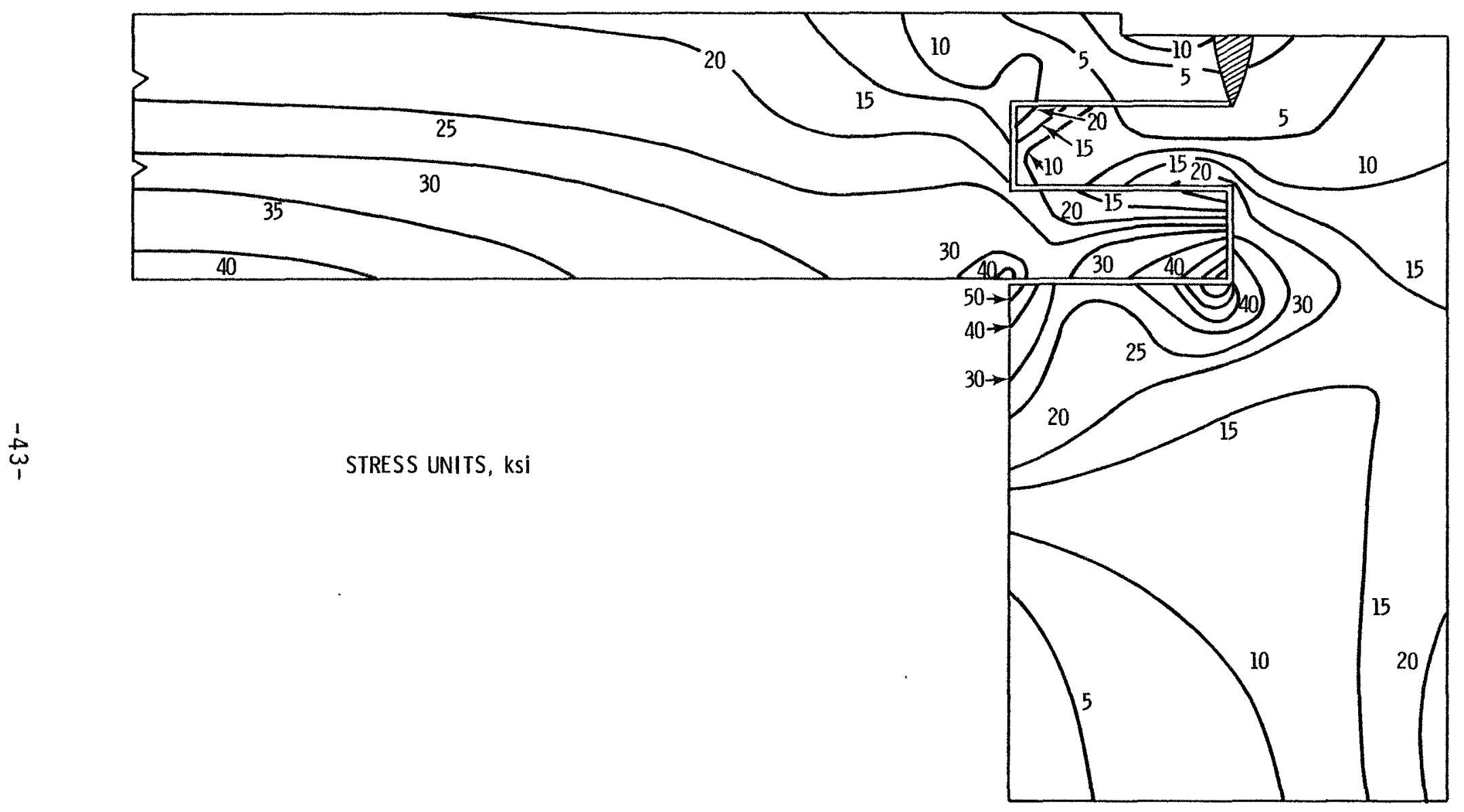

FIGURE 24. Calculated Contours of Effective Stress in Capsule End Cap for External Pressure of 14,500 psi (0.6-In. Wa11) 
page blank 
IMPACT AND PUNCTURE TESTS

Qualification testing requirements for impact and puncture are described in items 2 and 3 of the Appendix. The ability of the proposed Hastelloy $S$ capsule and end closure design to meet these requirements was evaluated by tests on capsules of the stand-in AISI-1018 steel. Because the design was basically so massive and rugged, there was little question of the capsule's ability to meet the test requirements if the material were in a tough, ductile condition. Therefore, the effort was directed toward determining if a minimum Charpy impact energy requirement was really needed for the outer capsule. Details of the impact and puncture tests and results are described in this section.

\section{DROP TESTS OF AISI-1018 STEEL CAPSULES}

The qualification testing requirements stated that the capsule must not leak when dropped from a height of $9 \mathrm{~m}$ onto an unyielding target in such a manner that maximum possible damage will result. In this study, the critical orientation was a corner drop ( $9^{\circ}$ off vertical) for which the center of gravity of the capsule was in alignment with the impact point. Under these conditions, the maximum damage to the end closure weld (shown in Figure 25) was expected to occur.

A concrete slab was constructed with a $0.5-i n$. thick steel surface and set into firm soil. The capsules were suspended from an adjacent tower at the prescribed orientation and dropped from the 9-m height with a quickrelease mechanism. It was desired to have pictures of the drop of sufficient resolution capability to allow measurement of the off-vertical capsule angle at impact. During initial tests, a high-speed 35-mm camera was used to record a set of test drops. A high-speed 16-mm movie camera was used to record the second set of tests. It was found that the $35-\mathrm{mm}$ camera produced sharp photographs, as shown in Figure 26, but was not fast enough to assure capture of more than one photograph during the last $8 \mathrm{ft}$ of the drop. The movie cavera was able to capture multiple photographs of the drop event but gave relatively poor capsule resolution when individual 


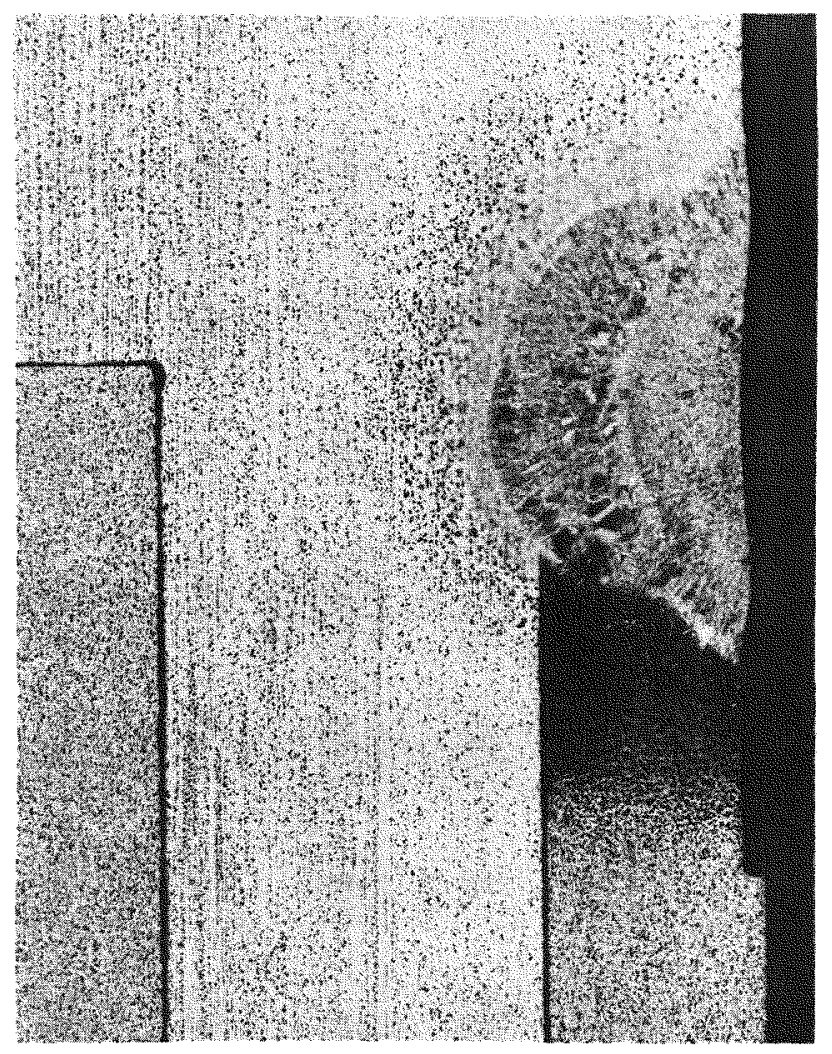

FIGURE 25. Photomicrograph of Full Penetration Closure Weld in AISI-1018 Steel Stand-In Outer Capsule (8x)

frames were enlarged to $8 \times 10 \mathrm{in}$. prints. Nevertheless, it is felt that the $16-\mathrm{mm}$ film yielded sufficient resolution to allow angle-of-strike measurements, and thus was used for recording subsequent capsule drops. It was also determined that the capsule drop and release mechanism functioned correctly and required only slight modification to be ready to use in subsequent stand-in capsule drops.

The initial drop tests were of stand-in outer capsules only, with no simulation of the complete ${ }^{90} \mathrm{SrF}_{2}$ heat source capsule. These tests were performed primarily to check the drop and photographic procedures. Capsules were impacted at both ambient and liquid nitrogen temperatures. No leakage was detected after these tests using a helium leak check technique. 


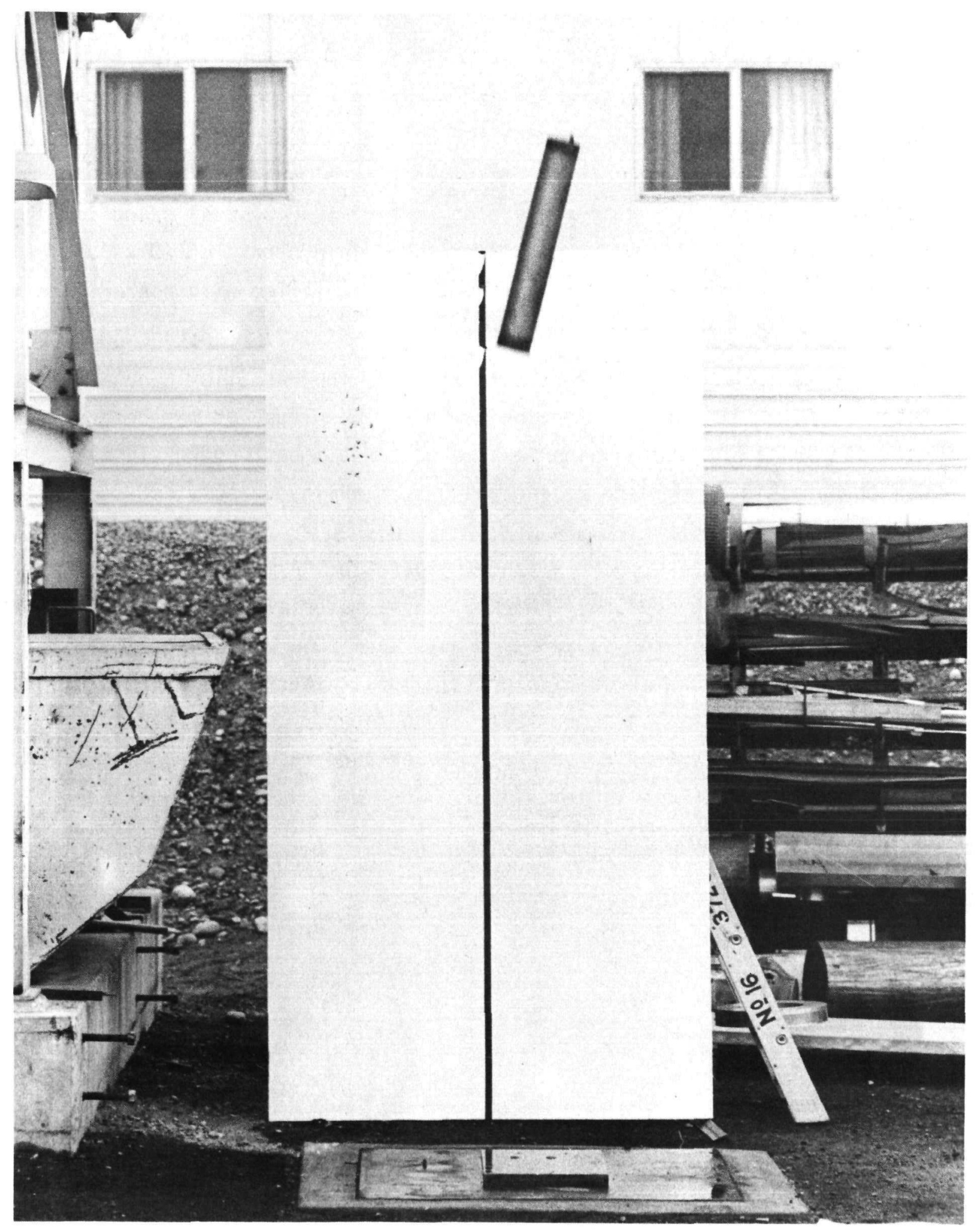

FIGURE 26. Thirty-Foot Drop Test of an AISI-1018 Steel Capsule 
The second series of tests was directed toward determining if a minimum impact energy requirement was needed for the outer capsule. To investigate this question, original capsule drop tests were supplemented with an additional test using a capsule having a much lower impact energy. Both capsules used in these drop tests were AISI-1018 steel stand-in capsules heat-treated to a room temperature yield stress of $40 \mathrm{ksi}$. The capsules contained a carbon steel inner capsule filled with nonradioactive $\mathrm{SrF}_{2}$ powder to simulate the completed ${ }^{90} \mathrm{SrF}_{2}$ heat source capsule.

The minimum impact energy anticipated in the Hastelloy $S$ outer capsule material after 10 years of service is $30 \mathrm{ft}-1 \mathrm{~b}$. Thus, it was desired to test the initial stand-in capsule at a 30-ft-lb impact energy level. This was to be achieved by determining the impact energy versus test temperature characteristics of the capsule material and then dropping the capsule at the test temperature needed to achieve $30 \mathrm{ft}-1 \mathrm{~b}$. A major complication developed in this procedure, however, as the material for the capsule walls and the material for the capsule end caps were from different AISI-1018 steel heats. Thus, when ductile-brittle impact energy curves were determined, different characteristic temperatures were found. The experimentally determined impact energy versus test temperature results for the two heats are shown in Figure 27.

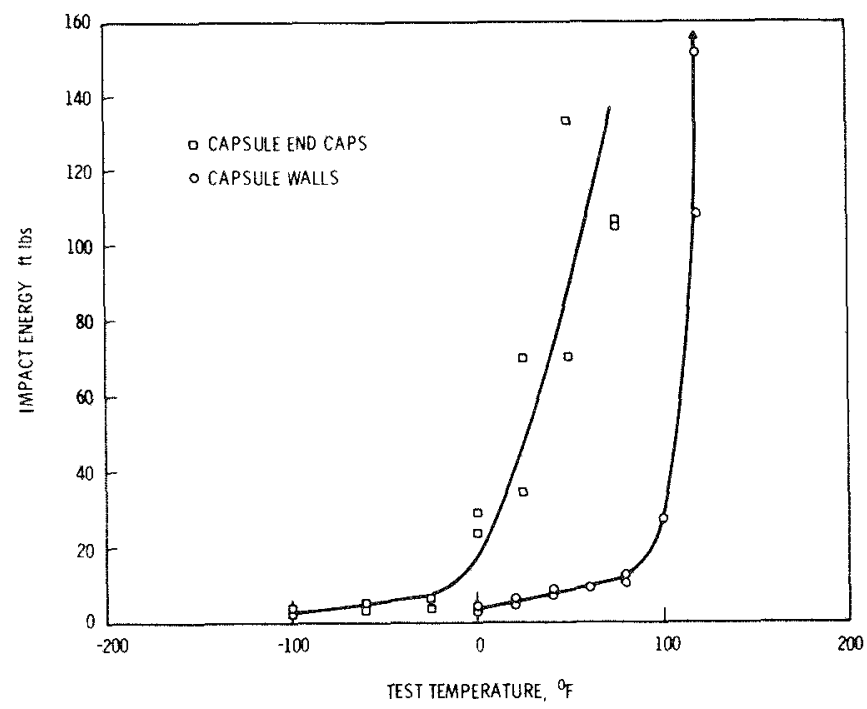

FIGURE 27. Charpy Impact Energy for AISI-1018 Steel Outer Capsule Components 
It was decided to remain conservative in the test program. The first test capsuTe was dropped at a temperature of $15^{\circ} \mathrm{F}$; the highest impact energy component (the end cap) exhibited $30 \mathrm{ft}-1 \mathrm{~b}$ and the capsule wall exhibited $7 \mathrm{ft}-1 \mathrm{~b}$ of impact energy. It was assumed that the weld area exhibited an impact energy bounded by these two extremes. This initial impact capsule was dropped $30 \mathrm{ft}$ without suffering any major damage, as can be seen in Figure 28. However, the end of the cap was slightly deformed on impact, as can be seen in Figure 29. Subsequent helium leak-checking verified that no impact-induced capsule cracking took place.

It was then decided to test a capsule with essentially no impact energy, to determine if inclusion of a minimum impact absorption energy in the capsule design criterion was required. A capsule was therefore tested at $-176^{\circ} \mathrm{C}$ by submersion in 1 iquid nitrogen. This test temperature resulted in less than $5 \mathrm{ft}-1 \mathrm{~b}$ of impact energy for the total capsule, and in the complete failure of the end cap section above the weld on the capsule end that hit the steel drop plate, as can be seen in Figure 30. It is believed that this impact failure did not occur upon initial outer capsule impact with the drop test steel plate, which would result in a compressive impact event in the capsule wa17. Rather, this impact failure is attributed to a "hammer" effect from the "floating" inner capsule impacting the end of the outer capsule, resulting in a tensile impact event.

It is believed that these results indicate the need for a minimum impact energy requirement, and that the $30 \mathrm{ft}-1 \mathrm{~b}$ of energy, as stipulated, are sufficient to assure this type of failure will not occur in the Hastelloy $S$ alloy outer capsules. In addition, it is believed that the hammer effect of the inner capsule against the outer capsule can be minimized by adding a spacer to remove or minimize the current gap between inner and outer capsules. 


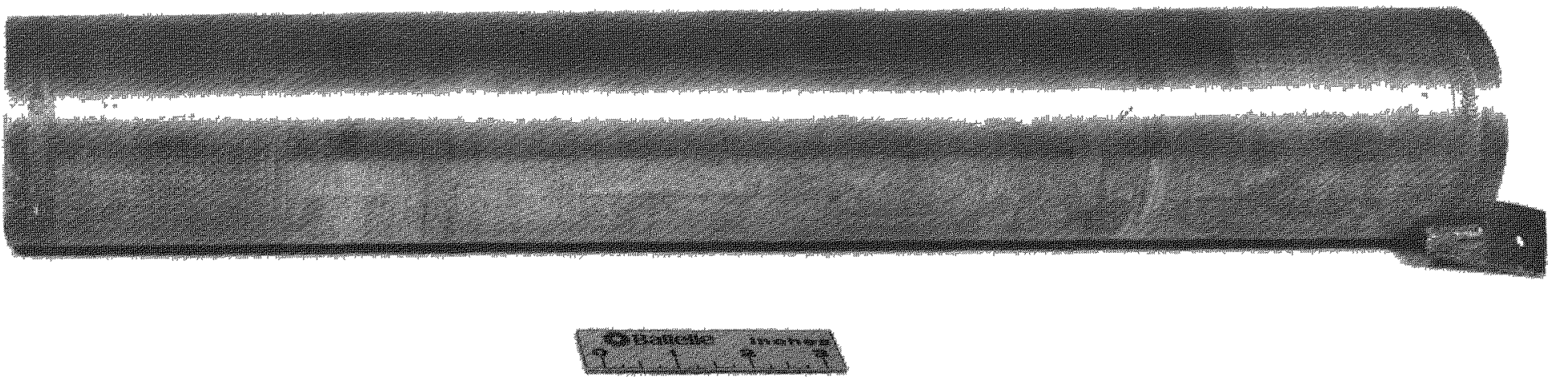

它

FIGURE 28. AISI-1018 Steel Stand-In Outer Capsule After Drop Test at $15^{\circ} \mathrm{F}$ 


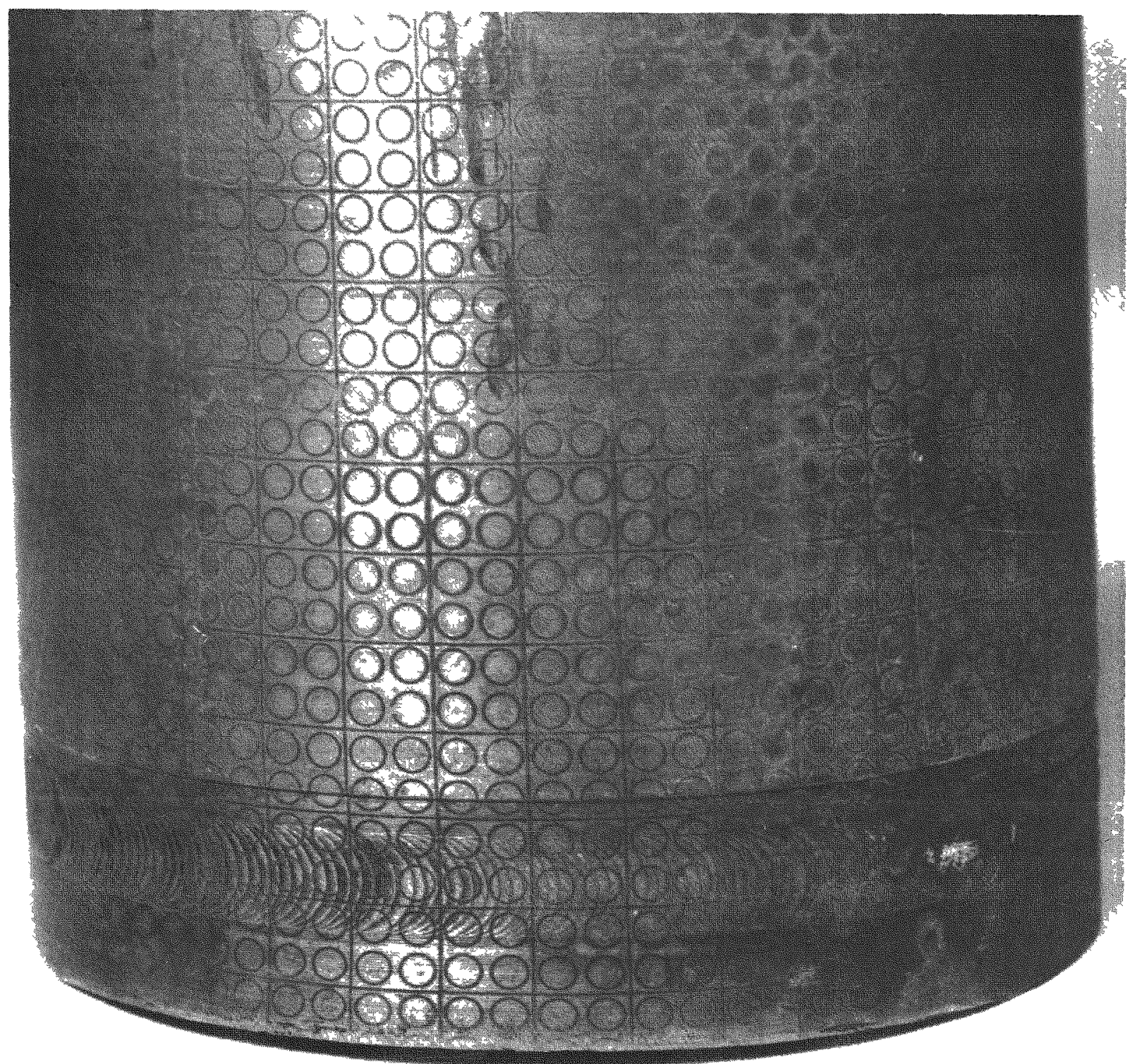

FIGURE 29. Impacted Corner of AISI-1018 Stee $T^{*}$ Stand-In Outer Capsule Showing STight Deformation After Drop Test at $15^{\circ} \mathrm{F}$ 



FIGURE 30. AISI-1018 Stee1 Stand-In Outer CapsuTe Tested at Liquid Nitrogen Temperature Showing Complete Brittle Failure of End Cap 


\section{PUNCTURE TESTS OF AISI-1018 STEEL CAPSULES}

The qualification testing requirements 1 isted in the Appendix state that the capsule must not leak when struck by a $2.5-\mathrm{cm}$ diameter steel billet with an impact energy equivalent to $7 \mathrm{kgm}$. Except for possible vulnerable locations at the weld and end caps, an impact of this magnitude was expected to have little effect on the AISI-1018 steel capsules.

The 0.5-in. wall thickness stand-in steel capsule used in the puncture testing was the same capsule that had withstood the 1000-bar hydrostatic test reported in a previous section of this report. The capsule was puncturetested at the three locations shown in Figure 31: at the middle of the capsule; at the inner edge of the capsule $1 \mathrm{id}$; and at the inner edge of the weld. The three puncture drops left slight indentations on the capsule surface but did not puncture the capsules, as evidenced by visual inspection and substantiated by subsequent helium leak-checking.

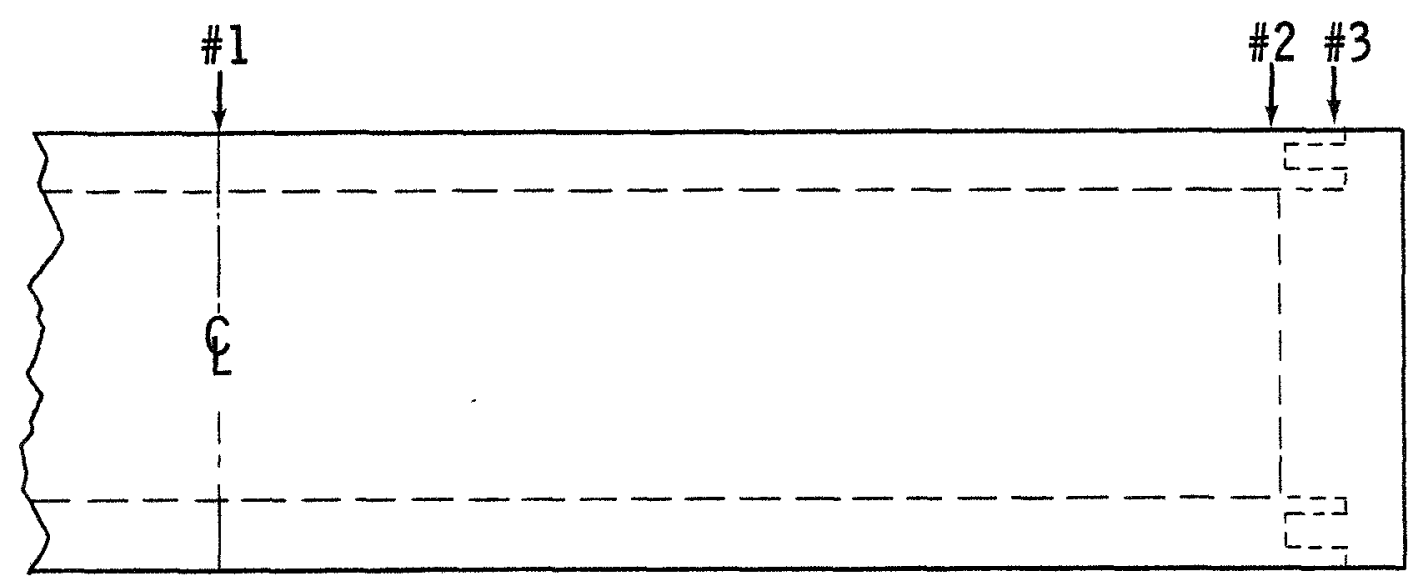

FIGURE 31. Locations of Three Puncture Tests on Steel Stand-In Capsule 


\section{-}

page blank 


\section{CONCLUSIONS}

A high integrity heat source outer capsule was designed to replace the present outer capsule of the WESF ${ }^{90} \mathrm{SrF}_{2}$ capsule in storage at Hanford. This outer capsule was designed to meet heat source qualification and licensing requirements. The proposed outer capsule, to be fabricated of Hastelloy $S$, is cylindrical with a wall thickness of $0.50 \mathrm{in.}$ One end may be integral with the capsule and, if so, would be 0.5 in. thick. The end cap is a 1.0-in. thick closure of special design to sustain qualification test loadings of external pressure and end impact. A mechanical interlock is used in the closure joint to provide the required strength, while minimizing seal welding requirements.

To meet qualification test requirements, the outer capsule design must withstand an external pressure of 14,500 psi (1000 bar) and a 9-m (30-ft) drop. Detailed stress analyses for the capsule were performed under these conditions. In addition, physical tests were performed for capsules of AISI-1018 carbon steel, which served as stand-ins for a prototype capsule of Hastelloy $S$ in an aged condition.

The capsule wa11 thickness was governed by the 14,500-psi pressure requirement. In-depth calculations were conducted to estimate the capsule collapse pressure for external pressure loading. Finite element stress analyses were performed to evaluate the effects of wall thickness capsule ovality, reinforcing effects of end caps, and material strain hardening. Stresses were also evaluated within the end closure for the qualification pressure of 14,500 psi. However, external pressure collapse tests of the AISI-1018 steel capsules showed that the stress calculations seriously overestimated the pressure capability of the outer capsule design. The recommended 0.5-in. wal1 thickness is based on the results of the experimental study. Possible reasons for the lack of agreement between the tests and the analyses have been evaluated. It appears the yield criteria of conventional plasticity theories for triaxial compression stress states did not perform well for the AISI-1018 low carbon steel. 
Based on the experimental tests, capsules of AISI-1018 steel with a 0.5in. wal1 will not collapse catastrophically at the 14,500-psi design pressure, although limited plastic deformation will occur. A reduction of the capsule wall thickness from $0.5 \mathrm{in}$. to perhaps $0.4 \mathrm{in}$. may be justified if the Hastelloy $S$ material behaves in a more predictable manner. However, any wall thickness reduction must be based on the results of future qualification tests for the Hastelloy $S$ material in a suitably aged condition.

Finite element analyses were used to perform initial evaluations of end closure performance under the impact loadings associated with the $30-\mathrm{ft}$ drop requirement. Calculations of the dynamic stress states showed that plastic deformation at the closure weld location of the proposed end closure design will be minimal.

The stress analyses and test results indicate that the proposed outer capsule will meet the heat source qualification requirements. Future tests will be conducted to experimentally verify that the Hastelloy $S$ outer capsule in the aged condition meets the structural integrity requirements. 
REFERENCES

American Society of Mechanical Engineers. 1977. ASME Boiler and Pressure Vessel Code, Section VIII Rules for Construction of Pressure Vessels, Division 2, Alternate Rules. New York, New York.

Bathe, K. J. 1976. ADINA - A Finite Element Program for Automatic Dynamic Incremental Nonlinear Analysis. Report 82448-7, Acoustics and Vibration Laboratory, Mechanical Engineering Department, Massachusetts Institute of Technology, Cambridge, Massachusetts.

Bradley, N. C. 1973. Isotopic Kilowatt Program Fuel Capsule Testing. ORNL-TM-4250, Oak Ridge National Laboratory, Oak Ridge, Tennessee.

Bridgeman, P. W. 1952. Studies in Large Plastic Flow and Fracture. McGrawHil1, New York, New York.

Davidson, T. E., C. S. Barton, A. M. Reiner, and D. P. Kendall. 1959. The Autofrettage Principle as Applied to High Strength Light Weight Gun Tubes. Watervliet Arsenal Report, Watervliet, New York.

Edwards, S. H. and C. P. Miller. 1939. "Effect of Combined Longitudinal Loading and External Pressure on the Strength of 0i1-We11 Casing." Presented to the American Petroleum Institute (Drilling and Production Practice) 1939 meeting, Chicago, I11 inois, pp. 483-502.

Grove, G. R., et a1. 1965. Plutonium-238 Isotopic Power Sources: A Summary Report. MLM-1270, Mound Laboratories, Miamisburg, Ohio.

Gupta, Y. M. 1977. "Pressure-Dependent Yield and Plastic Volume Change in High Strength Steels." Acta Metallurgica. 25:1509-1513.

Hammond, J.E. 1975. Cesium Chloride Capsule Testing for Special Form Qualification. ARH-CD-440, Atlantic Richfield Hanford Company, Richland, Washington.

Heise, O., and E. P. Esztergar. 1970. "Elastoplastic Collapse of Tubes Under External Pressure." Journal of Engineering for Industry. $92(4): 735-742$.

Key, S. W. 1974. HONDO - A Finite Element Computer Program for the Large Deformation Dynamic Response of Axisymmetric Solids. SLA-74-0039, Sandia Laboratories, Albuquerque, New Mexico (modified in June 1975).

Livsey, W. 0., and A. A. Junejo. 1976. "The Collapse of Heat Exchange Tubes With Ovality and Simulated Defects." Int. J. Pres. Ves. and Piping.

$4: 47-61$. 
Llorens, R. E. 1977. "Compression of Thick-Walled Tubes by External

Pressure." ASME, Journal of Pressure Vessel Technology. 99(4):516-522.

Michno, M. J., and W. N. Findley. 1975. "Subsequent Yield Surfaces for Annealed Mild Steel Under Servo-Controlled Strain and Load Histories: Aging Normality, Convexity, Corners, Bauschinger and Cross Effects." Journal of Engineering Materials and Technology. 97(1):25-32.

Nadai, A. 1950. Theory of Flow and Fracture of Solids. Vol. 1, 2nd ed. McGraw-Hi11, New York, New York.

Shappert, L. B. 1970. A Guide to the Design, Fabrication, and Operation of Shipping Casks for Nuclear Applications. ORNL-NSIC-68, Oak Ridge National Laboratory, Oak Ridge, Tennessee.

Timoshenko, S. P., and J. M. Gere. 1961. Theory of Elastic Stability. McGraw-Hi11, New York, New York.

Timoshenko, S. P., and J. N. Goodier. 1951. Theory of Elasticity. McGrawHi11, New York, New York. 


\section{APPENDIX}

QUAL IFICATION TESTING REQUIREMENTS

FOR THE ${ }^{90} \mathrm{SrF}_{2}$ HEAT SOURCE 


\section{APPENDIX}

\section{QUALIFICATION TESTING REQUIREMENTS FOR THE ${ }^{90}$ SrF 2 HEAT SOURCE}

The outer capsule of the ${ }^{90} \mathrm{SrF}_{2}$ heat source must meet the following requirements in both the as-fabricated and post-service conditions, without support from the inner capsule:

1. The capsule shall not leak at a rate greater than $10^{-8} \mathrm{~cm}^{3} / \mathrm{sec}$ after being subjected to an external pressure of 14,500 psi (1000 bar).

2. The capsule shall not leak at a rate greater than $10^{-8} \mathrm{~cm}^{3} / \mathrm{sec}$ when dropped from a height of $9 \mathrm{~m}$ (approximately $30 \mathrm{ft}$ ) onto a steel plate at least $1.25 \mathrm{~cm}$ (approximately $1 / 2 \mathrm{in.)}$ thick which has been wetfloated onto a concrete block with a mass of at least 10 times that of the capsule and set on firm soil. The steel plate shall be flat and horizontal and the capsule shall be dropped in such a manner that the maximum possible damage will result.

3. The capsule shal1 not leak at a rate greater than $10^{-8} \mathrm{~cm}^{3} / \mathrm{sec}$ after being struck by the flat face of a $2.5-\mathrm{cm}$ diameter (approximately 1 in.) steel billet with an impact energy equivalent to $7 \mathrm{kgm}$ (approximately $50 \mathrm{ft}-1 \mathrm{~b})$. The billet edges shall be rounded off to a radius of not less than $3 \mathrm{~mm}$, and the capsule shall rest on a lead sheet equal to or less than $25 \mathrm{~mm}$ thick with a Brinell hardness of 3.5 to 4.5 . The lead sheet shall cover a greater area than the capsule and shall rest on a smooth, solid surface. A fresh lead sheet shall be used for each test, and the capsule shall be struck in such a manner that the maximum possible damage will result.

4. The capsule shall not leak at a rate greater than $10^{-8} \mathrm{~cm}^{3} / \mathrm{sec}$ after being heated to its maximum operating temperature of $800^{\circ} \mathrm{C}$ and then plunged into a water-ethylene glycol solution at $32^{\circ} \mathrm{F}\left(0^{\circ} \mathrm{C}\right)$. The capsule shall remain for one hour in the circulating solution, which shall at no time exceed $41^{\circ} \mathrm{F}\left(5^{\circ} \mathrm{C}\right)$. 
5. The capsule shall pass a test (experimental and/or thermal analysis) such that the capsule remains capable of fuel containment during and after a one half-hour fire at $1475^{\circ} \mathrm{F}\left(802^{\circ} \mathrm{C}\right)$. The overpack capsule shall contain either a standard WESF ${ }^{90} \mathrm{SrF}_{2}$ inner capsule or the equivalent fuel (aS $\mathrm{SrF}_{2}$ ) contained in the WESF capsule, whichever condition is worse, and shall receive no supplemental cooling after the fire. The test (or calculation) shall be continued until no further material damage due to increasing temperature and/or accelerated fuel/ encapsulation material reactions at elevated temperature is possible.

6. The capsule must be sufficiently oxidation resistant that oxidation occurring during the service life of the heat source will not degrade the properties of the capsule to the extent that it cannot meet the other qualification requirements defined in this table. The oxidation requirement for the capsule is based on the conditions that:

a. The outer capsule surface temperature will not exceed $800^{\circ} \mathrm{C}$, and

b. The service 1 ife of the heat source will not exceed 10 years. The ability of the capsule to meet the oxidation requirement may be demonstrated by extrapolation of reliable short-term oxidation data using established procedures.

7. The capsule must provide sufficient resistance to seawater corrosion such that accidental exposure of the source to seawater for a period of one year will not degrade the properties of the capsule to the extent that it cannot meet the other qualification requirements defined in this table. This requirement is based on the assumption that a heat source which is accidentally exposed to a seawater environment will be retrieved from that environment within a period of one year. (a)

(a) It is anticipated that the material chosen for the outer capsule will be very resistant to seawater corrosion and that the capsule will be able to withstand exposure to seawater for periods much in excess of one year without suffering a serious degradation of properties. If, however, the heat source is to be used in undersea service, additional protection against seawater corrosion may be required. 


\section{DISTRIBUTION}

No. of

Copies

OFFSITE

A. A. Churm

DOE Patent Division

9800 S. Cass Avenue

Argonne, IL 60439

N. Goldenberg

DOE Advanced Nuclear Systems and Projects Division

Washington, DC 20545

T. J. Dobry, Jr.

DOE Advanced Nuclear Systems and Projects Division

Washington, DC 20545

T. J. Holl leman

DOE Advanced Nuclear Systems and Projects Division

Washington, DC 20545

A. P. Litman

DOE Advanced Nuclear Systems and Projects Division

Washington, DC 20545

J. J. Lombardo

DOE Advanced Nuclear Systems and Projects Division

Washington, DC 20545

3 W. C. Remini

DOE Advanced Nuclear Systems and Projects Division

Washington, DC 20545

B. J. Rock

DOE Advanced Nuclear Systems and Projects Division

Washington, DC 20545
No. of

Copies

N. R. Thielke

DOE Advanced Nuclear Systems and Projects Division

Washington, DC 20545

J. M. Maddox

DOE

E201

Washington, DC 20545

C. A. Cooley

DOE Waste Management Division Washington, DC 20545

D. C. Davis, Jr.

DOE Oak Ridge Operations Office P.O. Box E

Oak Ridge, TN 37830

W. T. Goldston

DOE Savannah River Operations Office

P. 0. Box A

Aiken, SC 29801

27 DOE Technical Information Center

L. J. Jardine

Argonne National Laboratory

9700 South Cass Avenue

Argonne, IL 60439

C. A. Alexander

Battel le Columbus Laboratories

505 King Avenue

Columbus, $\mathrm{OH} 43201$

W. R. Pardue

Battelle Columbus Laboratories

505 King Avenue

Columbus, $\mathrm{OH} 43201$ 
No. of

Copies

W. J. Zielenback

Battelle Columbus Laboratories

505 King Avenue

Columbus, $\mathrm{OH} 43201$

R. T. Huntoon

E. I. duPont deNemours \& Company Savannah River Laboratory

Aiken, SC 29801

E. H. Cooke-Yarborough

Electronics and Applied Physics Division

Building 347.3, AERE Harwell

Oxfordshire OXI1 ORA

GREAT BRITAIN

H. C. Carney

General Atomic Company

P.0. Box 81601

San Diego, CA 92138

S. E. Bronisz

Los Alamos Scientific Laboratory

P.0. Box 1663

Los Alamos, NM 87544

R. A. Kent

Los Alamos Scientific Laboratory

P.0. Box 1663

Los Alamos, NM 87544

R. N. R. Mul ford

Los Alamos Scientific Laboratory

P.0. Box 1663

Los Alamos, NM 87544

W. T. Cave .

Monsanto Research Corporation

Mound Laboratory (DOE)

Nuclear Operations

P.0. 32

Miamisburg, $\mathrm{OH} 45342$
No. of

Copies

R. Dewitt

Monsanto Research Corporation

Mound Laboratory (DOE)

Nuclear Operations

P.0. Box 32

Miamisburg, $\mathrm{OH} 45342$

H. H. Musselman, Tech. Dir.

Department of the Army

Headquarters, U.S. Army

Facilities Engineering Support Agency

Fort Belvoir, VA 22060

Officer in Charge

Lt. J. H. Vogt

Naval Nuclear Power Unit

Code 70

Port Hueneme, CA 93043

2 A. A. Arcuni

Naval Facilities Engineering Command

Office of Special Assistant Nuclear Programs (04N)

200 Stovall Street

Alexandria, VA 22332

F. N. Case

Oak Ridge National Laboratory

Oak Ridge, TN 37830

R. S. Crouse

Oak Ridge National Laboratory

Oak Ridge, TN 37830

K. W. Haff

Oak Ridge National Laboratory

Oak Ridge, TN 37830

J. Hammond

Oak Ridge National Laboratory

Oak Ridge, TN 37830 
No. of

Copies

J. R. Keiser

Oak Ridge National Laboratory

Oak Ridge, TN 37830

E. Lamb

Oak Ridge National Laboratory

Oak Ridge, TN 37830

C. L. Ottinger

Oak Ridge National Laboratory

Oak Ridge, TN 37830

J. C. Posey

Oak Ridge National Laboratory

Oak Ridge, TN 37830

A. C. Schaffhauser

Oak Ridge National Laboratory

Oak Ridge, TN 37830

P. Dick

Teledyne Energy Systems

$110 \mathrm{~W}$. Timonium Road

Timonium, MD 21093

R. Hannah

Teledyne Energy Systems

$110 \mathrm{~W}$. Timonium Road

Timonium, MD 21093

W. A. McDonald

Teledyne Energy Systems

$110 \mathrm{~W}$. Timonium Road

Timonium, MD 21093

P. Vogelberger

Teledyne Energy Systems

$110 \mathrm{~W}$. Timonium Road

Timonium, MD 21093

C. C. Silverstein

Westinghouse Astronuclear

Laboratory

P.0. Box 1086A

Pittsburgh, PA 15236
No. of

Copies

ONSITE

4 DOE Richland Operations Office

D. Bogon

W. A. Burns

R. E. Gerton

H. E. Ransom

8 Rockwell Hanford Operations

L. I. Brecke

H. H. Hopkins

J. D. Kaser

E. J. Kosiancic

T. H. May

D. Ramey

J. P. Sloughter

C. R. Stroup

36 Pacific Northwest Laboratory

D. G. Atteridge

A. J. Currie

H. T. Fullam (10)

M. H. Henry

R. P. Marshall

R. E. Nightingale

N. J. 01son

L. D. Perrigo

A. M. Platt

W. E. Sande

F. A. Simonen (8)

H. H. Van Tuyl

Technical Files (5)

Publishing Coordination (3) 